NIST Technical Note 2177

\title{
Assessing the Quality of As-Received 4340 Steel for the Production of NIST Charpy Reference Specimens
}

Enrico Lucon

May Martin 
NIST Technical Note 2177

\title{
Assessing the Quality of As-Received 4340 Steel for the Production of NIST Charpy Reference Specimens
}

\author{
Enrico Lucon \\ May Martin \\ Applied Chemicals and Materials Division \\ Material Measurement Laboratory
}

This publication is available free of charge from:

https://doi.org/10.6028/NIST.TN.2177

September 2021

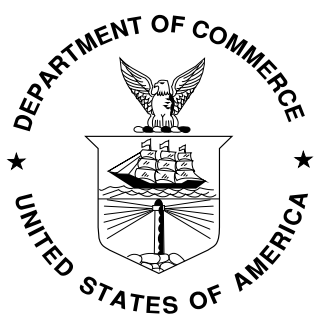

U.S. Department of Commerce

Gina M. Raimondo, Secretary

National Institute of Standards and Technology James K. Olthoff, Performing the Non-Exclusive Functions and Duties of the Under Secretary of Commerce for Standards and Technology \& Director, National Institute of Standards and Technology 
Certain commercial entities, equipment, or materials may be identified in this document in order to describe an experimental procedure or concept adequately. Such identification is not intended to imply recommendation or endorsement by the National Institute of Standards and Technology, nor is it intended to imply that the entities, materials, or equipment are necessarily the best available for the purpose.

National Institute of Standards and Technology Technical Note 2177 Natl. Inst. Stand. Technol. Tech. Note 2177, 38 pages (September 2021) CODEN: NTNOEF

This publication is available free of charge from: https://doi.org/10.6028/NIST.TN.2177 


\begin{abstract}
The Charpy Machine Verification Program at NIST in Boulder uses heat-treated 4340 steel for the production of indirect verification Charpy specimens at low- and high-energy level. Recently, a batch of steel purchased for the program turned out to be unacceptably inhomogeneous, causing several NIST Contractors to produce specimen lots that did not fulfill our variability requirements, despite repeated attempts at modifying the heat-treatment process. The whole batch of steel had to be eventually scrapped. In order to avoid such an occurrence in the future and develop an investigation procedure that can detect variability issues in the acceptance phase of newly purchased batches of 4340 steel, we have performed the following investigations and measurements on samples from "good" and "bad" heats: hardness measurements (Rockwell $\mathrm{C}$ and Vickers), instrumented Charpy tests, optical investigations, and texture analyses (including grain size measurements). Of all the parameters considered, we found that grain size can clearly differentiate between acceptable $(30 \mu \mathrm{m}$ to $40 \mu \mathrm{m})$ and unacceptable $(60 \mu \mathrm{m}$ to $70 \mu \mathrm{m})$ heats, and should therefore become the basis of future heat quality assessments. In support, hardness measurements can also be performed, while Charpy tests are not recommended in view of their relative experimental and economic burden.
\end{abstract}

\title{
Key words
}

4340 steel, grain size, hardness measurements, instrumented Charpy tests, NIST Charpy Program, optical investigations, steel variability, texture analysis. 
Table of Contents

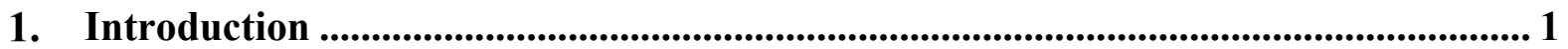

2. Material and Heats Investigated ....................................................................... 2

3. Tests and Investigations Performed.......................................................................... 2

3.1. Rockwell C Hardness Measurements ....................................................................... 2

3.2. Instrumented Charpy Tests............................................................................ 3

3.2.1. Non-instrumented Results (Absorbed Energy) ............................................. 3

3.2.2. Instrumented Results .............................................................................. 4

3.3. Optical Investigations and Texture Analysis of Steel Microstructure ..................... 6

3.4. Vickers Microhardness Measurements ................................................................ 10

4. Additional Investigations .............................................................................................. 11

4.1. Rockwell C Hardness Measurements ............................................................... 11

4.2. Vickers Microhardness Measurements .............................................................. 11

4.3. Grain Size .................................................................................................... 12

4.4. Final Assessment .......................................................................................... 12

5. Conclusions and Recommended Procedure ....................................................... 12

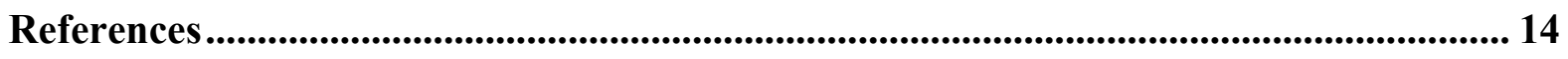

Appendix A: Compositional and Melting Requirements (Specifications) for 4340 Steel 15

Appendix B: Rockwell C measurements on GH1 and BH heats ................................... 17

Appendix C: Absorbed energy results from GH1, GH2, and BH heats ......................... 18

Appendix D: Instrumented impact results from GH1 and BH heats .............................. 19

Appendix E: Optical microscopy of GH1 and BH heats.................................................. 21

Appendix F: EBSD data for GH1 and BH heats............................................................ 25

Appendix G: Vickers microhardness measurements on GH1 and BH heats.................. 30

Appendix H: Vickers microhardness measurements on BL-1 and BL-2 blanks........... 32

\section{List of Tables}

Table 1 - Results of Rockwell C hardness measurements on GH1 and BH. ........................ 2

Table 2 - Overall Charpy test results for GH1, GH2, and BH (not instrumented)................. 3

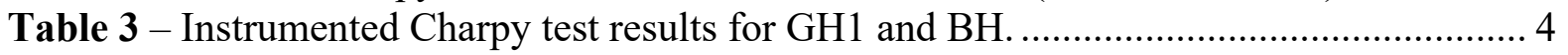

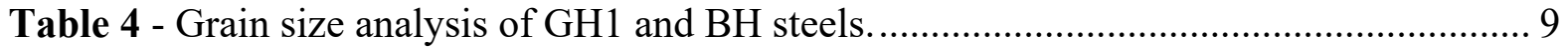

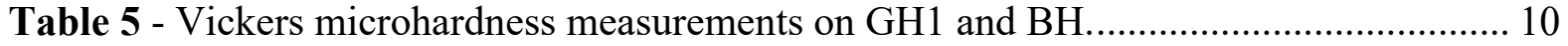

Table 6 - Vickers microhardness measurements on BL-1 and BL-2 samples. .................... 11 


\section{List of Figures}

Figure 1 - Distribution of HRC measurements for heats GH1 (left) and BH (right) steel...... 3 Figure 2 - Comparison between representative instrumented Charpy curves of GH1 and BH steels. 5

Figure 3 - Instrumented Charpy curves of fully brittle BH specimens............................. 5 Figure 4 - Comparison of GH1 and BH steel etched samples, showing the microstructure within the different planes of the bars...................................................................... 7

Figure 5 - High magnification comparison of $\mathrm{Z}$ planes for $\mathrm{GH} 1$ and $\mathrm{BH}$ steels. ................. 8

Figure 6 - Comparison of the EBSD results for the $\mathrm{Z}$ plane of $\mathrm{GH} 1$ and $\mathrm{BH}$.................... 9 Figure 7 - Orientations of Vickers microhardness measurements on GH1 and BH samples. 10 Figure 8 - Comparison between two blanks received from the successful Contractor and the previously examined $\mathrm{BH}$ results.

Figure 9 - Comparison of scans done at different resolutions for BH and GH1. "High resolution" corresponds to a step size of $3 \mu \mathrm{m}$, while "low resolution" has a step size of 10 $\mu \mathrm{m}$ and "very low resolution" is $25 \mu \mathrm{m}$. For the BH steel, the low- and very low-resolution scans were taken over an identical area. 


\section{Introduction}

More than 60 years ago, indirect verification of Charpy impact machines through testing reference specimens with certified values of absorbed energy was added to ASTM E23 [1], because the use of direct (physical/dimensional) verification alone could not explain some unacceptable differences among the results obtained by different machines on the same specimens [2]. It was found that in many cases, such differences could be traced back to interactions between the machine components and the specimens, and only testing with verification specimens could resolve these effects.

In the late 60's, the U.S. army (Watertown Arsenal, AMMRC) started a Charpy machine verification program for the production, certification, and distribution of reference specimens for the indirect verification of impact machines in the United States. In 1989, NIST in Boulder, Colorado took over the program, and Army personnel helped transfer the three reference Charpy machines used to certify verification specimens to Boulder [3]. These three machines are also defined by ASTM E23 as "master Charpy machines"; one of the original Army machines was replaced in the early 2000's with a similar one, but with higher capacity.

Nowadays, the NIST Charpy Machine Verification Program provides more than 1200 customers in 59 countries ${ }^{1}$ with Charpy reference specimens of three energy levels (low, high, and super-high) for the indirect verification of impact machines in accordance with both ASTM E23 and ISO 148-2 [4].

The program currently uses two steels, AISI 4340 and AISI 9310, appropriately heattreated, to produce reference specimens. The latter steel is currently used for super-high energy specimens (until the early 2010's, T-200 maraging steel was used), while the former steel has historically been used for low-energy and high-energy specimens.

Steels are bought in bulk, in the form of $1 / 2$ in. square bars approximately $6 \mathrm{ft}$. in length, typically once a year, in accordance with NIST specifications that address both the chemical composition and the steel production process.

In the overwhelming majority of cases, the purchased steel bars, compliant to our specifications, have been found satisfactory and fully adequate for the production of NIST certified indirect verification specimens, once heat-treated and machined by our Contractors. However, a batch of 4340 steel was recently found to be inhomogeneous and inadequate to produce acceptable (i.e., with sufficiently low variability) Charpy specimens for the NIST program, despite being in compliance with our specifications. Several low- and high-energy lots were produced by multiple Contractors, tested, and had to be eventually discarded due to excessive variability. This obviously caused economic burden to the program, which could not be avoided.

To avoid a similar occurrence in the future, we decided to develop a procedure for the early detection of potential inhomogeneity issues in newly purchased heats of 4340 steel. This report describes several steps that have been undertaken in order to identify those investigations and tests which can be most effective in intercepting "defective" steel batches. Every activity has been performed on 4340 steel blanks ${ }^{2}$, fully machined specimens, or

\footnotetext{
${ }^{1}$ Data referring to the end of Fiscal Year 2019 (September 2019).

${ }^{2}$ A steel "blank" is an unnotched bar with approximate dimensions $11 \mathrm{~mm}$ (cross section dimensions) and $58 \mathrm{~mm}$ (length), from which a final Charpy specimen is machined after heat treatment.
} 
generic pieces from an established "good" heat and from the previously identified "bad" heat. Not all activities were found to be equally significant in detecting inhomogeneity issues, as will be detailed in the following sections.

\section{Material and Heats Investigated}

AISI 4340 [5] is a nickel-chromium-molybdenum alloy steel known for its toughness and its ability to attain high strengths in the heat-treated condition. It has very good fatigue resistance. It can be heat treated to high strength levels while maintaining good toughness, wear resistance and fatigue strength levels, combined with good atmospheric corrosion resistance, and strength. NIST specifications on chemical composition and production process are provided in Appendix A.

The activities described in this report were performed on the following three heats of raw 4340 steel:

1) "good" heat T0726 [GH1], which had been successfully used to obtain several acceptable low-energy and high-energy Charpy specimen lots;

2) "good" heat J1234 [GH2], which had also been successful in producing acceptable lots; and

3) "bad" heat H5855 [BH], which had not yielded acceptable Charpy lots for multiple Contractors.

\section{Tests and Investigations Performed}

\subsection{Rockwell C Hardness Measurements}

Rockwell C hardness (HRC) measurements are routinely performed on Charpy verification specimen lots before specimens are tested. Although no requirement related to hardness exists in NIST specifications, HRC measurement are used as a check on the absorbed energy level and their scatter is often correlated to the variability of Charpy absorbed energy results. Moreover, the minimum HRC value for fully heat-treated lowenergy specimens is specified as $44 \mathrm{HRC}$.

Hardness was measured on 50 raw (non heat-treated) Charpy specimens, 25 from $\mathrm{GH} 1$ and 25 from BH, before they were tested as described in section 3.2. Mean values and other basic statistics are reported in Table 1. Individual measurements are provided in Appendix B.

Table 1 - Results of Rockwell C hardness measurements on GH1 and BH.

\begin{tabular}{|c|c|c|c|c|}
\hline Steel & $\overline{\text { HRC }}$ & $\boldsymbol{s}$ & $\begin{array}{c}\boldsymbol{C V} \\
\mathbf{( \% )}\end{array}$ & Range \\
\hline GH1 & 10.9 & 1.93 & 17.7 & 6.1 \\
\hline BH & 12.9 & 2.07 & 16.0 & 10.8 \\
\hline
\end{tabular}

LEGEND $\quad \overline{H R C}=$ mean hardness.

$s=$ standard deviation of HRC.

$C V=$ coefficient of variation $(\overline{H R C} / s)$.

Range $=$ difference between maximum and minimum hardness. 
The mean value for $\mathrm{BH}$ is 2 points higher than $\mathrm{GH} 1$, while standard deviation is only marginally higher for $\mathrm{BH}$. The distribution of measured values looks significantly different between the two heats, as illustrated by the bar charts in Figure 1.
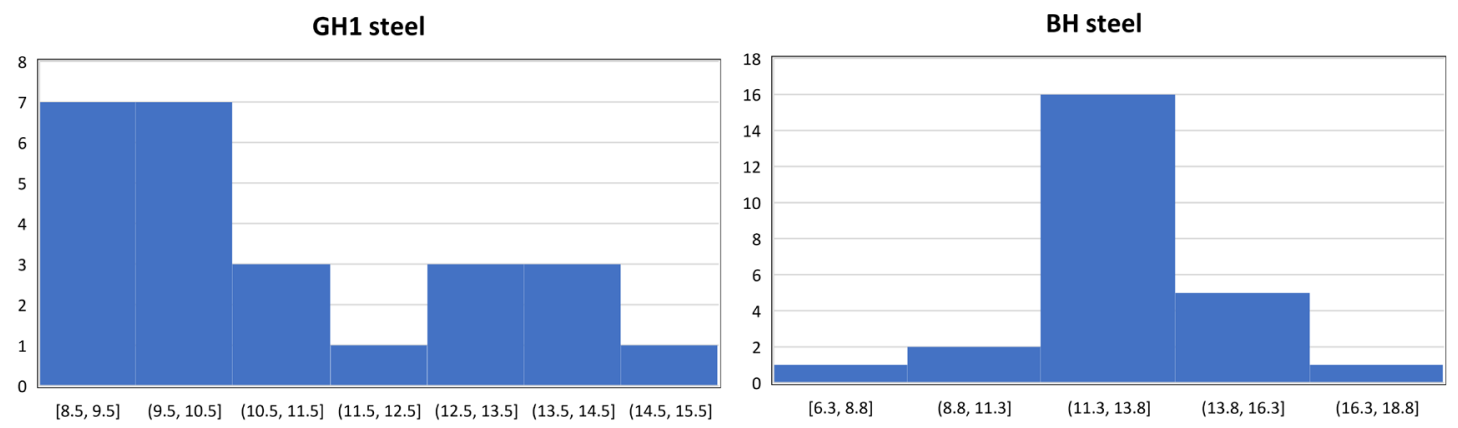

Figure 1 - Distribution of HRC measurements for heats GH1 (left) and BH (right) steel.

The following statistical tests were performed on the two sets of Rockwell C hardness measurements.

- A two-tailed two sample t-test assuming equal variances ${ }^{3}$ returned a statistically significant difference between the hardness of the two steel heats with a $95 \%$ confidence level $(p=0.000786)^{4}$.

- Grubbs' test [6,7] detected no statistical outliers for GH1, while the lowest value measured on $\mathrm{BH}$ (specimen $13, \mathrm{HRC}=6.3$ ) was flagged as a statistical outlier with a $95 \%$ confidence level.

- The Shapiro-Wilk normality test [8] did not recognize either hardness distribution (Figure 1) as normal.

\subsection{Instrumented Charpy Tests}

Seventy-five Charpy tests were performed on three 4340 heats: 25 on GH1 specimens, 25 on $\mathrm{GH} 2$ specimens, and 25 on $\mathrm{BH}$ specimens. Instrumented tests were performed on $\mathrm{GH} 1$ and $\mathrm{BH}$, while tests on $\mathrm{GH} 2$ were not instrumented.

\subsubsection{Non-instrumented Results (Absorbed Energy)}

Overall absorbed energy $(K V)$ results are displayed in Table 2. Individual test results are provided in Appendix C.

Table 2 - Overall Charpy test results for GH1, GH2, and BH (not instrumented).

\begin{tabular}{|c|c|c|c|c|c|c|c|}
\hline \multirow{2}{*}{ Steel } & $\bar{K} \boldsymbol{K}$ & $\boldsymbol{S}_{\boldsymbol{K} \boldsymbol{V}}$ & $\boldsymbol{C V}$ & $\boldsymbol{\sigma}$ & $\boldsymbol{\sigma}_{\overline{\boldsymbol{K V}}}$ & Range & \multicolumn{2}{|c|}{ Outliers Detected? } \\
\cline { 7 - 8 } & $(\mathbf{J})$ & $(\mathbf{J})$ & $(\boldsymbol{\%})$ & $(\mathbf{J})$ & $(\mathbf{J})$ & Box-and-Whiskers & Grubbs' Method \\
\hline $\mathrm{GH} 1$ & 25.839 & 2.869 & 11.1 & 0.574 & 12.85 & YES (1L) & YES (1L) \\
\hline $\mathrm{GH} 2$ & 32.898 & 6.556 & 19.9 & 1.311 & 21.98 & NO & NO \\
\hline $\mathrm{BH}$ & 17.322 & 3.825 & 22.1 & 0.765 & 13.55 & YES (3L) & NO \\
\hline
\end{tabular}

\footnotetext{
${ }^{3}$ Here and in the remainder of this investigation, every t-test was preceded by a two-sample F-test for Variances. If this latter test indicated equality of variances, a two-sample t-test assuming equal variances was performed. Otherwise, a two-sample t-test assuming unequal variances was conducted.

${ }^{4}$ If the calculated probability, $p$, is lower than 0.05 (assuming a level of confidence $\alpha=0.95$ ), the difference between mean values is considered statistically significant.
} 
LEGEND $\quad \overline{K V}=$ mean absorbed energy.

$s_{K V}=$ standard deviation of absorbed energy.

$C V=$ coefficient of variation $\left(\overline{K V} / s_{K V}\right)$.

$\sigma_{\overline{K V}}=$ standard error of the mean absorbed energy.

Range $=$ difference between maximum and minimum absorbed energy.

Outliers: $\mathrm{L}=$ low outlier (low absorbed energy).

$\mathrm{BH}$ returned the lowest average energy $(\overline{K V})$ and the highest coefficient of variation $(C V)$, as well as the largest number of outliers detected by the box-and-whiskers method ${ }^{5}$. On the other hand, GH2 exhibited the highest standard deviation, standard error of the mean, and range. As far as outliers are concerned, GH1 is the only condition for which Grubbs' method (which is more restrictive than box-and-whiskers) detected an outlier.

Based on statistical two-tailed t-tests for $\overline{K V}, \mathrm{BH}$ is significantly different than both GH1 $\left(p=9.74 \times 10^{-12}\right)$ and GH2 $\left(p=1.23 \times 10^{-12}\right)$. However, by the same approach, GH1 and $\mathrm{GH} 2$ are also statistically different from each other $\left(p=2.25 \times 10^{-5}\right)$.

Hence, Charpy energy seems to highly depend on the individual steel heat, and does not appear to be a good indicator of the quality (or lack thereof) of raw 4340 steel.

\subsubsection{Instrumented Results}

For each of the instrumented Charpy tests performed on $\mathrm{GH} 1$ and $\mathrm{BH}^{6}$, the following characteristic parameters were determined: force at general yield $\left(F_{g y}\right)$ and maximum force $\left(F_{m}\right)$, corresponding displacement values $\left(s_{g y}\right.$ and $\left.s_{m}\right)$, and instrumented energies at maximum force $\left(W_{m}\right)$ and test end $\left(W_{\mathrm{t}}\right)$. In addition, the elastic compliance, $C_{e l}$, was estimated from the initial elastic portion of the tests.

For each characteristic parameter, average values and coefficients of variation $(\mathrm{CV})$ are reported in Table 3. Individual test results are provided in Appendix D.

Table 3 - Instrumented Charpy test results for GH1 and BH.

\begin{tabular}{|c|c|c|c|c|c|c|c|c|}
\cline { 2 - 9 } \multicolumn{1}{c|}{} & Steel & $\begin{array}{c}\boldsymbol{F}_{\boldsymbol{g} \boldsymbol{y}} \\
(\mathbf{k N})\end{array}$ & $\begin{array}{c}\boldsymbol{F}_{\boldsymbol{m}} \\
(\mathbf{k N})\end{array}$ & $\begin{array}{c}\boldsymbol{s}_{\boldsymbol{g} \boldsymbol{y}} \\
(\mathbf{m m})\end{array}$ & $\begin{array}{c}\boldsymbol{s}_{\boldsymbol{m}} \\
(\mathbf{m m})\end{array}$ & $\begin{array}{c}\boldsymbol{W}_{\boldsymbol{m}} \\
(\mathbf{J})\end{array}$ & $\begin{array}{c}\boldsymbol{W}_{\boldsymbol{t}} \\
(\mathbf{J})\end{array}$ & $\begin{array}{c}\boldsymbol{C}_{\boldsymbol{e l}} \\
(\mathbf{m m} / \mathbf{k N})\end{array}$ \\
\hline \multirow{2}{*}{$\begin{array}{c}\text { Average } \\
\text { values }\end{array}$} & $\mathrm{GH} 1$ & 13.40 & 18.42 & 0.27 & 1.53 & 22.47 & 25.09 & 0.00819 \\
\cline { 2 - 9 } $\begin{array}{c}\text { Standard } \\
\text { deviations }\end{array}$ & $\mathrm{BH} 1$ & 13.97 & 16.70 & 0.27 & 0.94 & 12.28 & 17.28 & 0.01000 \\
\cline { 2 - 9 } & $\mathrm{BH}$ & 0.88 & 0.57 & 0.01 & 0.30 & 4.87 & 4.54 & 0.00400 \\
\hline \multirow{2}{*}{$\mathrm{CV}$} & $\mathrm{GH} 1$ & $4.2 \%$ & $6.0 \%$ & $6.6 \%$ & $16.3 \%$ & $19.9 \%$ & $11.9 \%$ & $7.1 \%$ \\
\cline { 2 - 9 } & $\mathrm{BH}$ & $6.3 \%$ & $3.4 \%$ & $4.5 \%$ & $31.7 \%$ & $39.6 \%$ & $26.3 \%$ & $40.0 \%$ \\
\hline
\end{tabular}

$\mathrm{BH}$ yielded higher $C V$ than GH1 for most characteristic parameters, except $F_{m}$ and $s g y$. For instrumented energies, values of $C V$ for $\mathrm{BH}$ are twice as large, or more, than those of GH1.

The outcomes of two-sample t-tests on every characteristic parameter indicated that there is a statistically significant difference (level of confidence $=0.95$ ) between the two steels for $F_{m}, s_{m}, W_{m}$, and $W_{t}$. The difference is not significant for $F_{g y}, s_{g y}$, and $C_{e l}$.

\footnotetext{
${ }^{5}$ The box-and-whiskers method classifies as an outlier a data point falling below the first quartile minus $1.5 \times$ the difference between third and first quartile, or above the third quartile plus $1.5 \times$ the difference between third and first quartile.

${ }^{6}$ Instrumented data were not recorded for one of the $\mathrm{BH}$ specimens tested (BH-21).
} 
Figure 2 compares instrumented force/time curves for two selected specimens from GH1 and BH. Specifically, the specimens with calculated absorbed energy $\left(W_{t}\right)$ closest to the series average were selected, GH1-9 (25.22 J) and BH-23 (17.64 J) respectively. The figure shows that the curves are very similar up to the point of general yield, and that $\mathrm{BH}$ experiences unstable fracture much earlier than $\mathrm{GH} 1$.

Finally, it's worth noting that three $\mathrm{BH}$ samples $(\mathrm{BH}-3, \mathrm{BH}-19$, and $\mathrm{BH}-22)$ exhibited a fully brittle behavior without noticeable plastic deformation (no occurrence of general yield), see Figure 3. This did not occur with any of the GH1 samples tested.

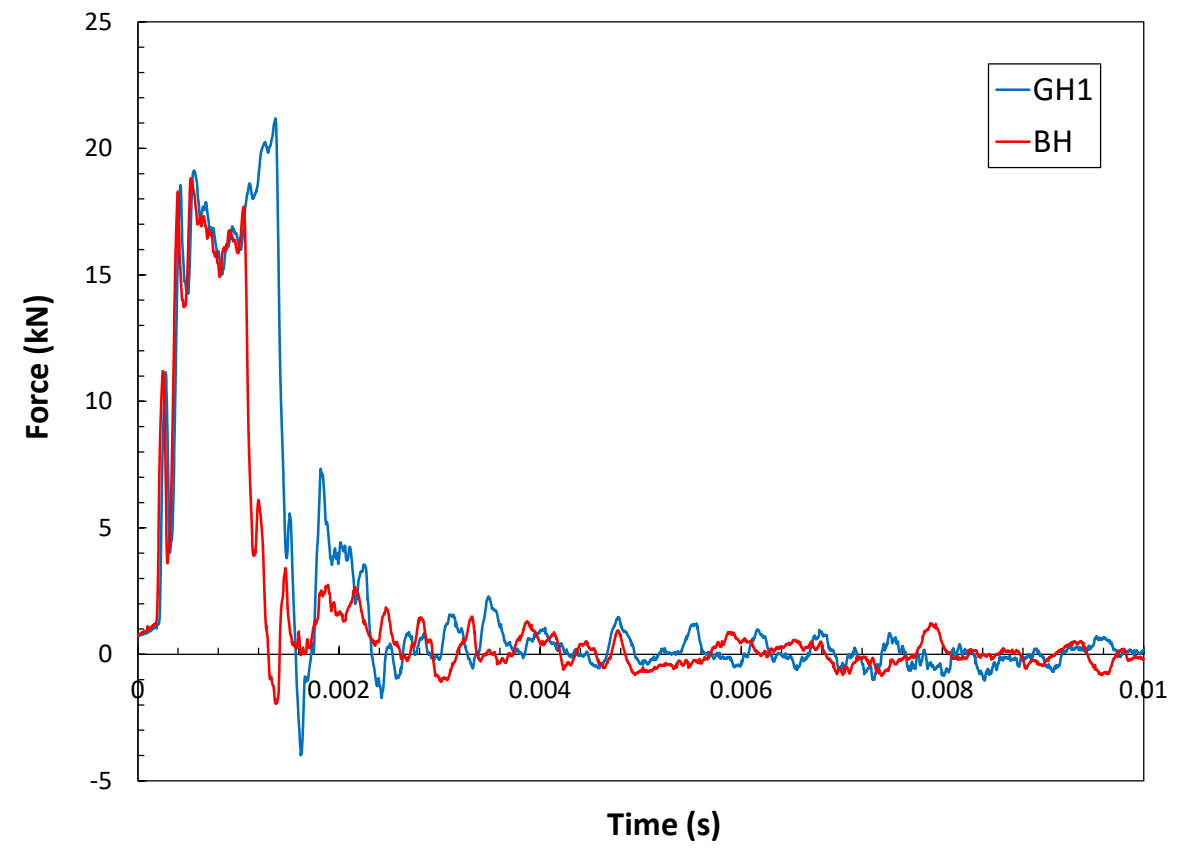

Figure 2 - Comparison between representative instrumented Charpy curves of GH1 and BH steels.

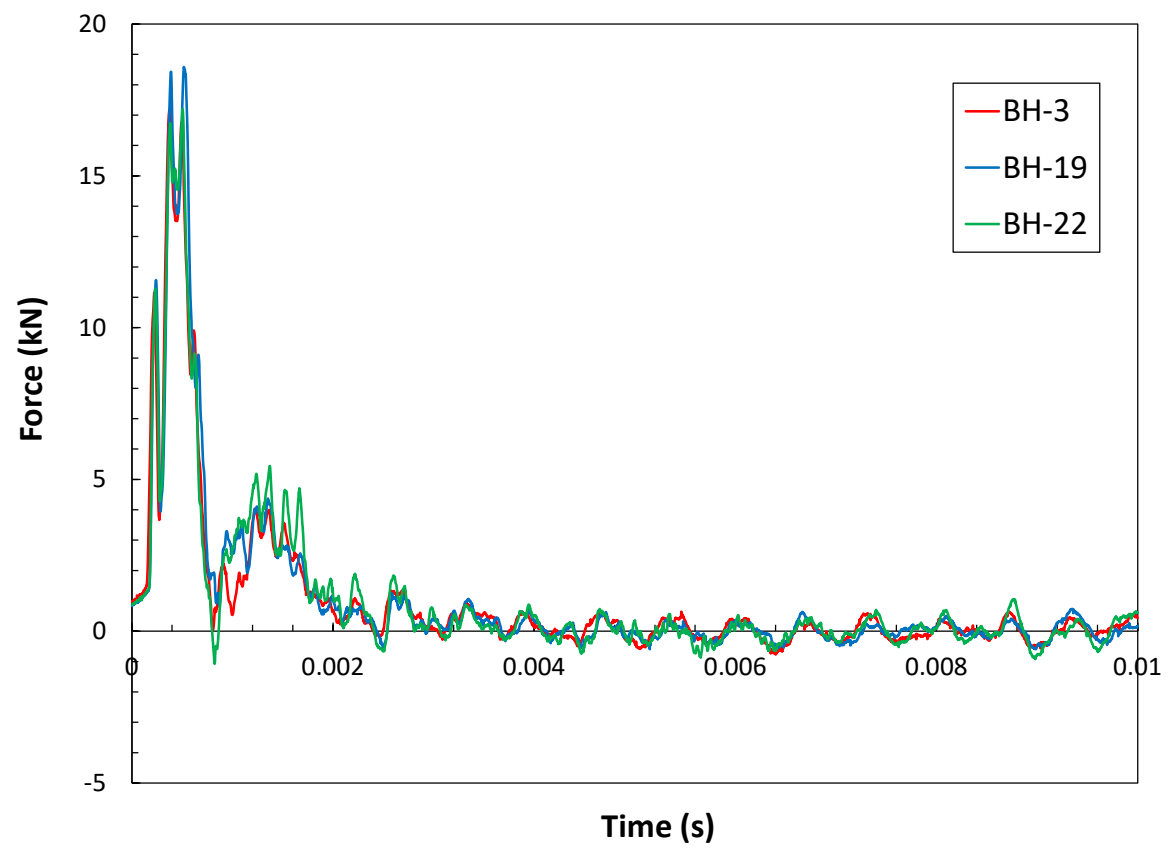

Figure 3 - Instrumented Charpy curves of fully brittle BH specimens. 


\subsection{Optical Investigations and Texture Analysis of Steel Microstructure}

Three blanks from GH1 and three blanks from BH were sectioned for microstructural characterization. The blanks were cut into 5 pieces, resulting in 2 end pieces and three pieces, approximately $10 \mathrm{~mm}$ long, that were prepared for microstructural analysis to examine the 3 directional planes of the blanks. The planes are named after the direction normal. The long axis of the blanks were dubbed the $\mathrm{Z}$ direction. The $\mathrm{X}$ and $\mathrm{Y}$ directions for the $\mathrm{GH} 1$ blanks were based upon the "NIST" stamp on one end: holding the sample to read "NIST" correctly, $\mathrm{X}$ was the horizontal direction, and $\mathrm{Y}$ was the vertical direction. The $\mathrm{BH}$ steel blanks did not have a "NIST" stamp, and so X and Y directions were assigned randomly; as there is no way to know if the "NIST" stamp is applied uniformly, there is likely a randomness to the $\mathrm{X}$ and $\mathrm{Y}$ directions on blanks from the GH1 batch as well. However, this ensured a consistency of direction between the three samples cut from each blank.

The three sections of each blank were mounted in conductive epoxy and marked to show the two directions of each plane (i.e. the $\mathrm{Y}$ and $\mathrm{Z}$ directions on the $\mathrm{X}$ plane). The samples were ground flat (simultaneously) until all traces of the surface oxide and machining layer on the $\mathrm{X}$ and $\mathrm{Y}$ planes were gone. The samples were then polished down to $0.05 \mu \mathrm{m}$ colloidal silica to create a mirror finish. For optical microscopy analysis, samples were etched with $2 \%$ nital (nitric acid in methanol) solution to reveal grain boundaries. Afterward, samples were repolished (from $10 \mu \mathrm{m}$ to $0.05 \mu \mathrm{m}$ ) to a mirror finish for electron backscattered diffraction (EBSD) analysis in a scanning electron microscope (SEM).

Optical examination of the etched samples focused on examining differences between the two steels and any variation along the different directions of the sample. The three directional samples from one bar of each type of steel (BH, and GH1) were selected for etching and optical examination. Images of all 6 of the etched samples are shown in Appendix E, and the results are summarized here. First, the samples appear to be fairly homogenous in a given observed plane, and there are not large gradients in grain size, secondary phases, or macrostructure across the observed planes from the center to the edges. Second, there is evidence of a directional macrostructure in the $\mathrm{Z}$ direction, which is more prominent in the good steel than in the bad, reminiscent of that derived from rolling-type processing. This macrostructure is unsurprising, given the forming process for a square crosssection bar. 

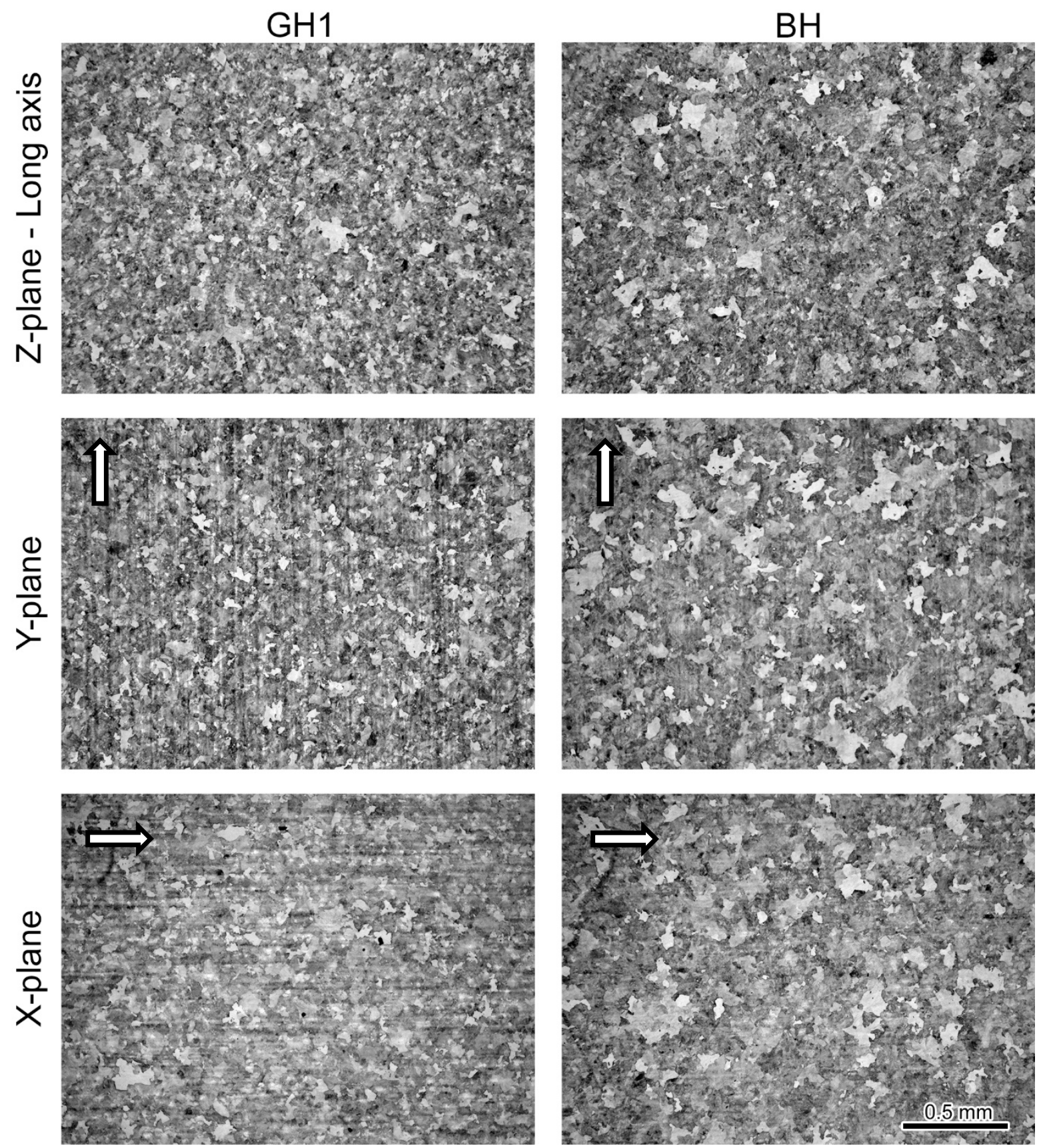

Figure 4 - Comparison of $\mathrm{GH} 1$ and $\mathrm{BH}$ steel etched samples, showing the microstructure within the different planes of the bars. White arrows indicate the Z-direction.

If the two steels are compared (Figure 4), it is clear that there is a significant difference in grain size, but otherwise the microstructures are similar. Comparing the microstructures at higher magnification (Figure 5), the similarities are more evident. The microstructure is very similar, with the relative amount of (likely) martensite grains (darker/speckled grains) to ferrite grains (lighter/cleaner grains) being similar, but slightly more numerous larger grains appearing in the BH steel. 

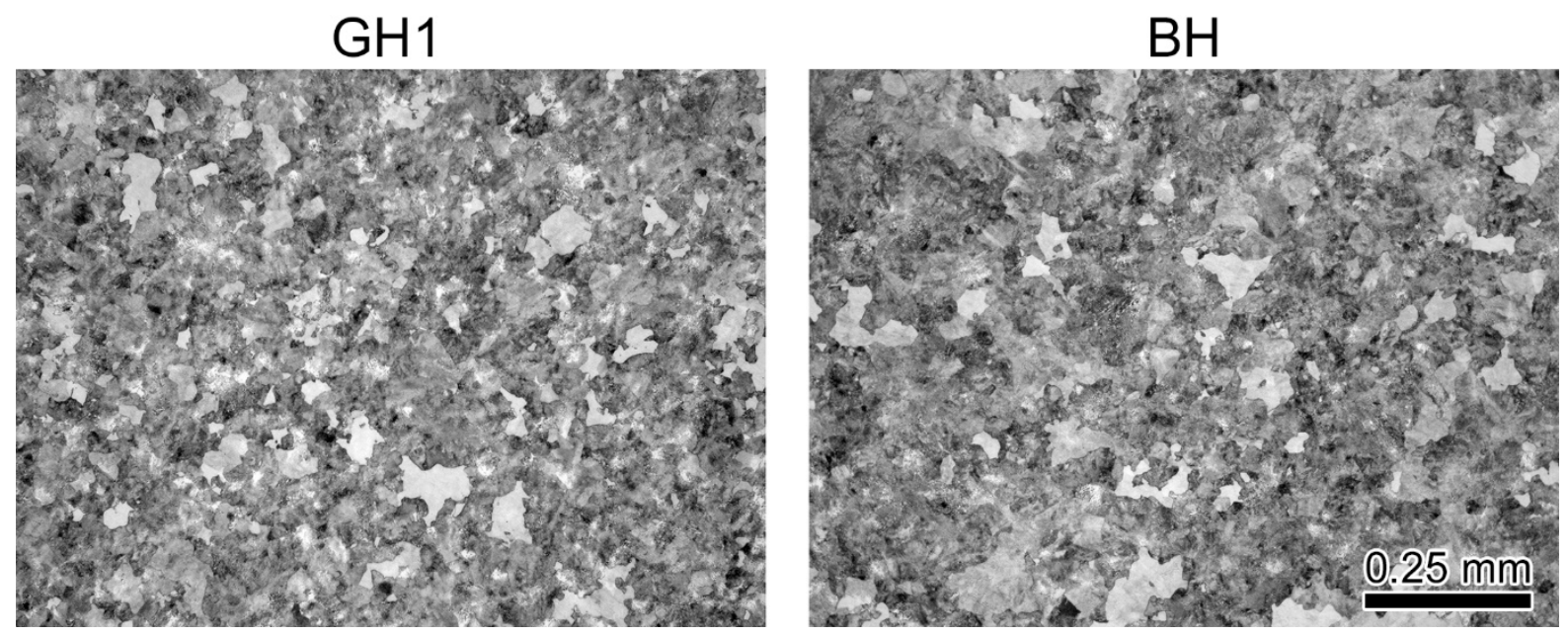

Figure 5 - High magnification comparison of Z planes for GH1 and BH steels.

EBSD analysis was performed on a SEM operated at $30 \mathrm{kV}$. Scan sizes were $1 \mathrm{~mm} \times$ $1 \mathrm{~mm}$ with a step size between 1 and $4 \mu \mathrm{m}$ to best capture the range of grain sizes, as well as sufficient data for texture analysis. These scans take between 6 and 12 hours, depending upon the step size and the EBSD camera settings (which are based upon the electron gun performance during the scan).

The EBSD data collected is reported in Appendix F, which includes the orientation mapping showing coloring based on the crystallographic direction perpendicular to the scan plane normal and some texture data for the direction perpendicular to the scan plan normal. Texture analysis is an automated process where the orientation information of each pixel is binned and presented as heat-map inverse-pole-figures. This indicates which orientations are the most common. These inverse pole figures have been normalized to the same intensity scale.

Figure 6 shows a side-by-side comparison of the EBSD data of the $\mathrm{Z}$ plane from a $\mathrm{GH} 1$ and a BH steel specimen. There is a clear difference in grain size, as suggested by the optical microscopy analysis. The texture looks similar, with a slightly stronger $\{101\}$ texture in the BH steel, although this could be an artifact due to the difference in the number of grains between the two scans. 
$\mathrm{GH} 1$

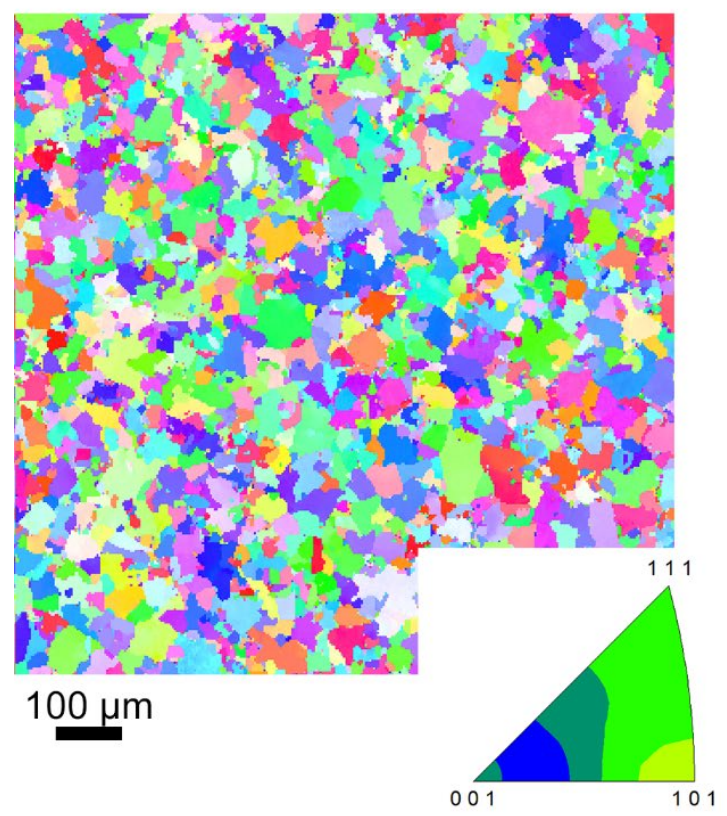

$\mathrm{BH}$

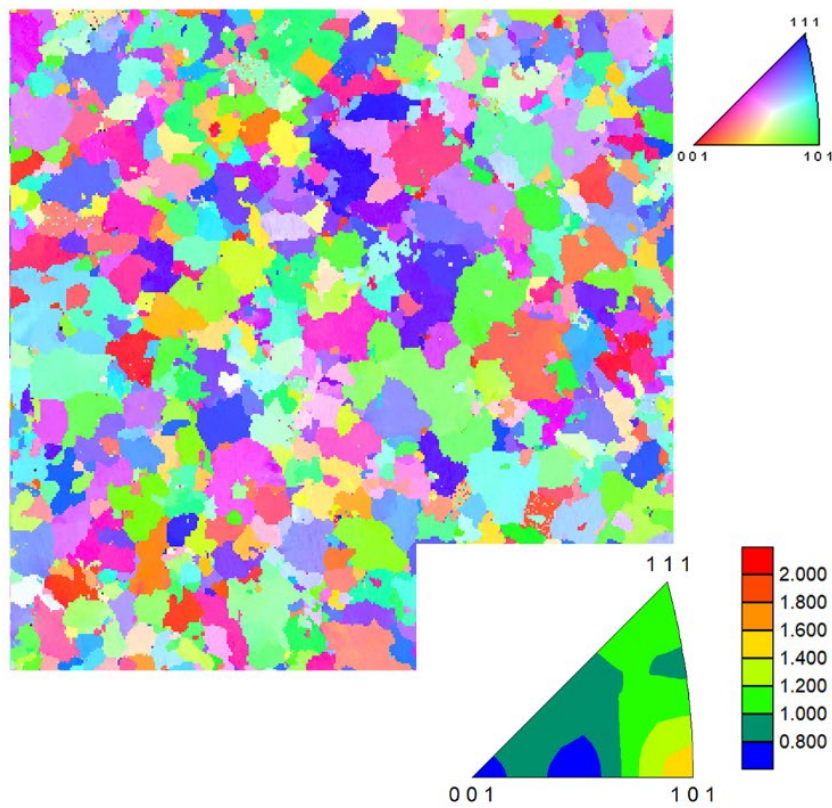

Figure 6 - Comparison of the EBSD results for the $\mathrm{Z}$ plane of GH1 and $\mathrm{BH}$.

Grain size was calculated from the EBSD data, an automated process which assumes contiguous areas of similar orientation are grains, and calculates an average diameter of the grains. To avoid noisy pixels from skewing the average, grains were only counted if they were more than 2 pixels in width. Average grain size is based upon area fraction, instead of number of grains, as this better represented the data and the difference between the GH1 and $\mathrm{BH}$ heats. The standard deviation reported for the grain sizes is in the range $20-30 \mu \mathrm{m}$.

However, due to the large number of grains in each scan $(\sim 1500)$, the error of the mean is on the order of $0.5 \mu \mathrm{m}$. So, while there is a large variation in the size of individual grains, the mean values are a reliable indicator of differences in grain size between samples.

Table 4 - Grain size analysis of GH1 and BH steels.

\begin{tabular}{|c|c|c|c|c|c|c|c|c|c|}
\hline \multirow{2}{*}{ Heat } & \multirow{2}{*}{$\begin{array}{c}\text { Sample } \\
\text { Id }\end{array}$} & \multicolumn{3}{|c|}{ Direction } & \multirow{2}{*}{ Heat } & \multirow{2}{*}{$\begin{array}{c}\text { Sample } \\
\text { Id }\end{array}$} & \multicolumn{3}{|c|}{ Direction } \\
\hline & & Z plane & Y plane & $\mathrm{X}$ plane & & & $\mathrm{Z}$ plane & Y plane & $X$ plane \\
\hline \multirow{3}{*}{ GH1 } & 1 & 47.8 & 41.4 & 46.6 & \multirow{3}{*}{ BH } & 1 & 66.8 & 66.3 & 71.8 \\
\hline & 2 & 38.2 & 35 & 34.9 & & 2 & 67.6 & 73 & 70.4 \\
\hline & 3 & 26.2 & 25.5 & 26.1 & & 3 & 58.5 & 60.8 & 62.3 \\
\hline \multicolumn{2}{|c|}{ Average } & 37.4 & 34.0 & 35.9 & \multicolumn{2}{|c|}{ Average } & 64.3 & 66.7 & 68.2 \\
\hline \multicolumn{2}{|c|}{ Stand. Deviation } & 8.8 & 6.5 & 8.4 & \multicolumn{2}{|c|}{ Stand. Deviation } & 4.1 & 5.0 & 4.2 \\
\hline
\end{tabular}

The grain size results are shown in Table 4. The GH1 heat has a smaller average grain size, at $35.8 \mu \mathrm{m}$ it is approximately half that of the $\mathrm{BH}$ heat at $66.4 \mu \mathrm{m}$ (averages of $\mathrm{X}$, $\mathrm{Y}$, and $\mathrm{Z}$ directions). Interestingly, a larger range in grain sizes was observed in $\mathrm{GH} 1$, resulting in a standard deviation of $8 \mu \mathrm{m}$, compared to only $4.7 \mu \mathrm{m}$ in $\mathrm{BH}$. 


\subsection{Vickers Microhardness Measurements}

Vickers microhardness (HV) measurements were taken on 6 samples/blanks, 3 from $\mathrm{GH} 1$ and 3 from $\mathrm{BH}$. Measurements were performed by means of a microhardness tester, with a test load of $500 \mathrm{gf}$ and a dwell time of $13 \mathrm{~s}$. HV was measured on each sample (mounted in conductive epoxy as described in section 3.3) along its cross section in two perpendicular directions, so that microhardness for each heat was measured twice per plane in every direction (X, Y, Z - see Figure 7) over the 3 samples of a given heat. Measurements were taken in 20 positions, spaced by approximately $0.5 \mathrm{~mm}$, following the double-pointed arrows shown in Figure 7.

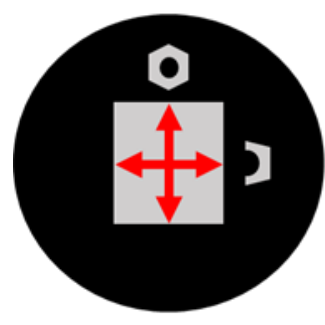

SAMPLE 1

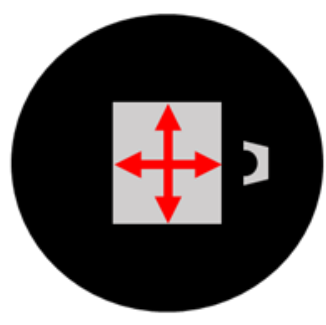

SAMPLE 2

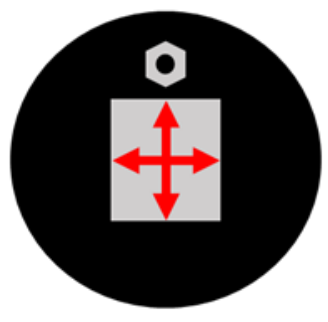

SAMPLE 3

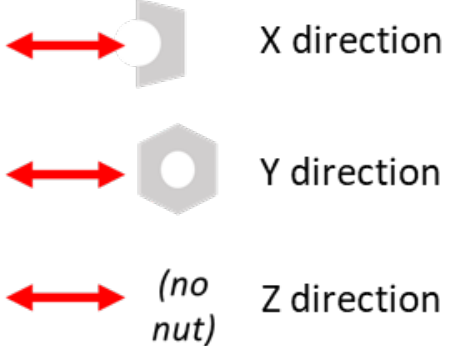

nut)

Figure 7 - Orientations of Vickers microhardness measurements on GH1 and BH samples.

Mean values, coefficients of variation, and ranges are presented in Table 5 for each heat, sample, and orientation. BH yielded higher Vickers hardness than GH1, while the differences in $C V$ and range are small (consistent with the HRC measurements in Table 1). Individual $\mathrm{HV}$ values are reported in Appendix G.

Table 5 - Vickers microhardness measurements on GH1 and BH.

\begin{tabular}{|c|c|c|c|c|c|c|}
\hline Heat & Sample & Direction & Average & St. dev. & $\mathrm{CV}$ & Range \\
\hline \multirow{6}{*}{ GH1 } & \multirow{2}{*}{1} & $\mathrm{X}$ & 203.5 & 6.1 & $3.0 \%$ & 20 \\
\hline & & $\mathrm{Y}$ & 204.3 & 4.4 & $2.8 \%$ & 20 \\
\hline & \multirow{2}{*}{2} & $\mathrm{X}$ & 207.0 & 5.8 & $2.1 \%$ & 21 \\
\hline & & Z & 204.4 & 7.7 & $2.7 \%$ & 23 \\
\hline & \multirow{2}{*}{3} & $\mathrm{Y}$ & 206.7 & 5.6 & $3.7 \%$ & 34 \\
\hline & & $\mathrm{Z}$ & 206.3 & 6.4 & $3.1 \%$ & 18 \\
\hline \multicolumn{3}{|c|}{ All samples } & 205.4 & 6.1 & $3.0 \%$ & 34 \\
\hline \multirow{6}{*}{$\mathrm{BH}$} & \multirow{2}{*}{1} & $\mathrm{X}$ & 216.5 & 6.2 & $2.8 \%$ & 27 \\
\hline & & $\mathrm{Y}$ & 214.4 & 6.8 & $3.5 \%$ & 30 \\
\hline & \multirow{2}{*}{2} & $X$ & 214.8 & 7.5 & $3.2 \%$ & 24 \\
\hline & & $\mathrm{Z}$ & 214.8 & 6.3 & $3.2 \%$ & 24 \\
\hline & \multirow{2}{*}{3} & $\mathrm{Y}$ & 218.4 & 6.8 & $2.9 \%$ & 22 \\
\hline & & Z & 222.2 & 6.6 & $3.0 \%$ & 22 \\
\hline \multicolumn{3}{|c|}{ All samples } & 216.8 & 7.1 & $3.3 \%$ & 36 \\
\hline
\end{tabular}


A two-sample, two-tailed t-test with $95 \%$ confidence level was performed, and found the difference in overall mean values between $\mathrm{GH} 1(\overline{H V}=205.4)$ and $\mathrm{BH}(\overline{H V}=216.8)$ to be extremely significant $\left(p=1.29 \times 10^{-30}\right)$.

Within-heat differences among the three tested samples were statistically assessed by means a one-way analysis of variance (single-factor ANOVA) [9]. The results indicated that HV differences between samples are not significant for GH1 $(p=0.1454)$ and significant for $\mathrm{BH}(p=0.00056)$, thus showing that the variability of $\mathrm{BH}$ is larger than $\mathrm{GH} 1$.

\section{Additional Investigations}

The inhomogeneity issues of heat H5855 were discovered after three of the four NIST Charpy Contractors failed to produce any acceptable lots using that heat. However, the fourth Contractor managed to supply successful Charpy lots at both low- and high-energy levels using the same "questionable" material.

In order to confirm that the successful Contractor had indeed been using heat H5855, we performed some additional investigations on two non-heat-treated blanks (BL-1 and BL-2) that the Contractor shipped to NIST.

\subsection{Rockwell C Hardness Measurements}

HRC was measured on opposite ends of the blanks. The averages of the two measurements were 13.3 and 14.2, respectively. Both values are within \pm 1 standard deviation of the mean value previously measured for $\mathrm{BH}(\overline{\mathrm{HRC}}=12.9 \pm 2.07$, see Table 1). Both averages are outside \pm 1 standard deviation of the mean value for GH1 $(\overline{\mathrm{HRC}}=10.9 \pm$ 1.93, see Table 1).

\subsection{Vickers Microhardness Measurements}

$\mathrm{HV}$ microhardness measurements were taken along two normal directions ( $\mathrm{X}$ and $\mathrm{Y}$ ) on BL-1 and BL-2 blanks, using the procedure already described in Section 3.4. The results (mean values, coefficients of variation, and ranges) are shown in Table 6. Individual measurements are reported in Appendix H.

Table 6 - Vickers microhardness measurements on BL-1 and BL-2 samples.

\begin{tabular}{|c|c|c|c|c|}
\hline Sample & Axis & Average & CV (\%) & Range \\
\hline \multirow{2}{*}{ BL-1 } & X & 214.2 & 4.4 & 38 \\
\cline { 2 - 5 } & Y & 216.0 & 5.9 & 46 \\
\hline \multirow{2}{*}{ BL-2 } & X & 210.9 & 3.1 & 20 \\
\cline { 2 - 5 } & Y & 212.8 & 3.8 & 30 \\
\hline \multicolumn{2}{|c|}{ Average } & $\mathbf{2 1 3 . 5}$ & $\mathbf{4 . 3}$ & $\mathbf{3 3 . 5}$ \\
\hline
\end{tabular}

Similar to HRC measurements, the average value of HV for the two blanks (last row of Table 6) falls within \pm 1 standard deviation of the previously measured mean value for $\mathrm{BH}(\overline{\mathrm{HV}}=216.8 \pm 6.69)$ and outside \pm 1 standard deviation of the mean value for $\mathrm{GH} 1(\overline{\mathrm{HV}}=$ $211.4 \pm 6.00)$, see Table 5 . 


\subsection{Grain Size}

Due to the above result showing similar grain sizes across the different directions, only the $\mathrm{Z}$ plane (longitudinal direction of the blanks) was examined for these two blanks. As can be seen in Figure 8, the two blanks show microstructure that corresponds closely to the previously examined BH samples. The grain sizes are $73 \mu \mathrm{m}$ and $64 \mu \mathrm{m}$ for the two blanks. This suggests that the success of this Contractor is due to their processing technique, and not due to variations within the steel batch. Therefore, even lots similar to BH could be useable for the NIST Charpy Program as long as they are appropriately heat-treated and processed.
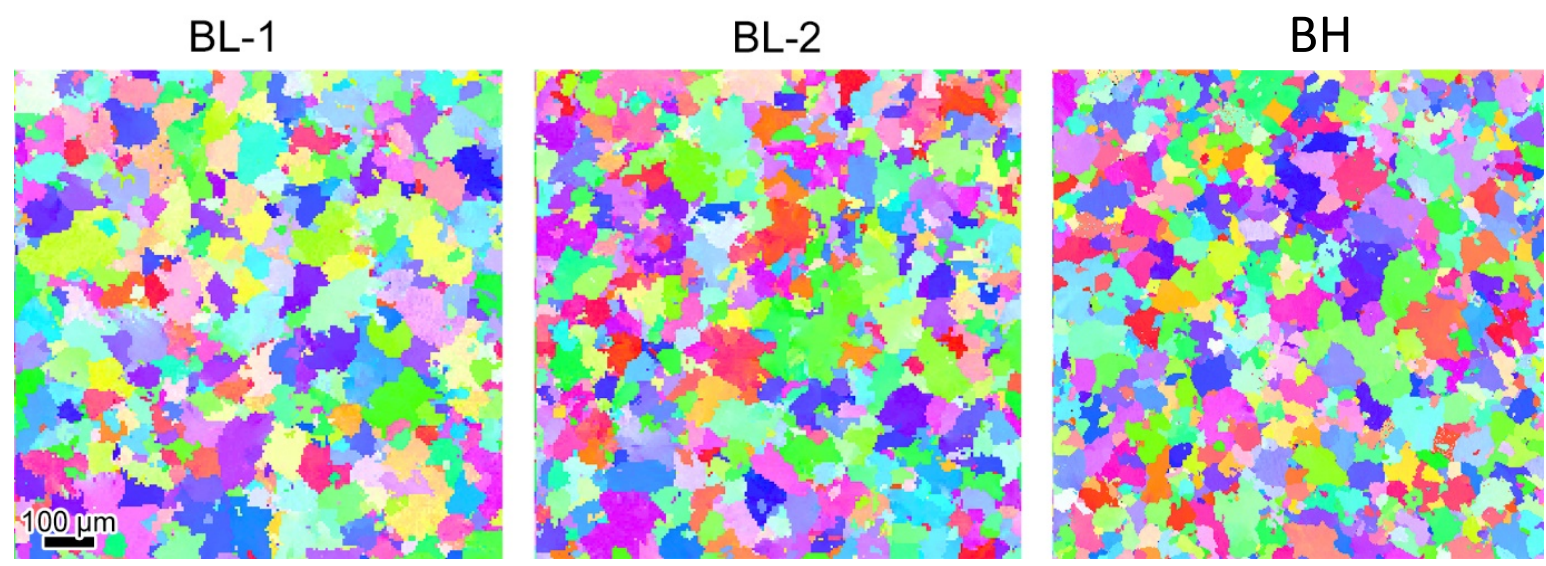

Figure 8 - Comparison between two blanks received from the successful Contractor and the previously examined $\mathrm{BH}$ results.

\subsection{Final Assessment}

Based on all the investigations performed (hardness and grain size measurements), we can confirm that the heat that the successful Contractor worked with is indeed the "questionable" $\mathrm{H} 5855$ heat.

Clearly, the reason of this success consists in some unique feature of the heat treatment procedure performed by the Contractor, which however cannot be disclosed to NIST for confidentiality reasons.

\section{Conclusions and Recommended Procedure}

Every investigation performed in this study (Rockwell C hardness measurements, Vickers microhardness measurements, instrumented Charpy tests, optical investigations, and texture analyses) has shown a clear difference between the "good" heats (GH1 and GH2) and the "bad" heat (BH). In many cases, differences have been confirmed by simple statistical tests (t-tests).

However, from a procedural standpoint, with a view on establishing a relatively quick and inexpensive procedure to verify the quality of newly purchased raw 4340 steel bars before dispatching them to Charpy Contractors, it appears that the most reliable indicator of the difference between the two steel batches resulted from the measurement of grain size based on microstructural analyses.

While EBSD analysis was used to determine the grain size, it can also be determined by optical analysis, so it is worth discussing which technique would be most efficient. While 
certain shortcuts can be taken in sample preparation for optical analysis that would be unacceptable for EBSD analysis, the sample preparation procedure is virtually identical when properly done. And while optical microscopy itself is a quicker technique than EBSD scanning in an SEM, any grain size measurement analysis would be predominantly a manual process, such that the automated grain size analysis from EBSD data may be worth the extra time in the laboratory. In addition, distinguishing grain boundaries for this material appears quite difficult. The main downside is that the EBSD scans presented previously took 6 to 12 hours each. But these were relatively high-resolution scans to ensure that there was sufficient data to make conclusions about the microstructure. This leads to the question of whether faster scans can be used to get the grain size information as a quick assessment process. For EBSD scans, a logical rule of thumb is two pixels per grain, which would correspond to 15 $\mu \mathrm{m}$ for $\mathrm{GH} 1$ or $30 \mu \mathrm{m}$ for $\mathrm{BH}$. This would take scan times down from over 6 hours to 45 minutes and 10 minutes respectively. The results of such scans can be seen in Figure 9, with $10 \mu \mathrm{m}$ and $25 \mu \mathrm{m}$ step sizes. As can be seen, the "very low resolution" scan is very pixelated, while the "low resolution" scan shows adequate resolution of the grains, even in GH1, though pixilation is more obvious there. There is an impact on the grain size measurement. For the BH steel, the original grain size measurement was $70.4 \mu \mathrm{m}$, while the low- and very low-resolution scans yielded $72.7 \mu \mathrm{m}$ and $78.4 \mu \mathrm{m}$. For the GH1 steel, the low-resolution scans gave a grain size of $40.3 \mu \mathrm{m}$ compared to the original grain size measurement $(35 \mu \mathrm{m})$. In both cases, the increase in step size resulted in an increase in measured grain size, due to the loss of the smaller grains which are not picked up. However, this is still enough to differentiate between the two steel batches.

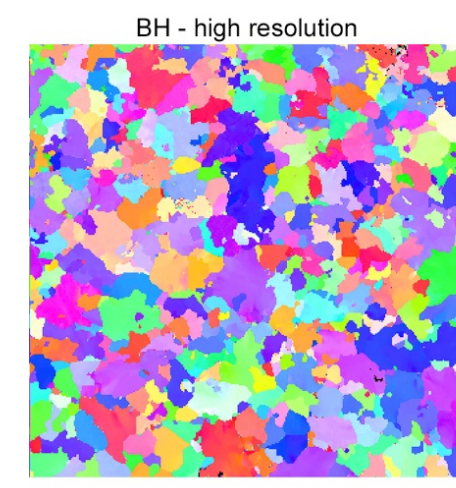

$\mathrm{GH} 1$ - high resolution

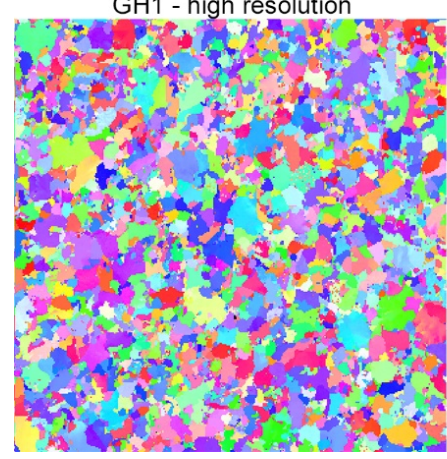

$\mathrm{BH}$ - low resolution

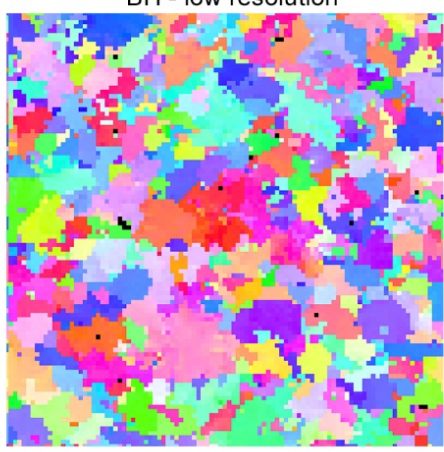

$\mathrm{GH} 1$ - low resolution

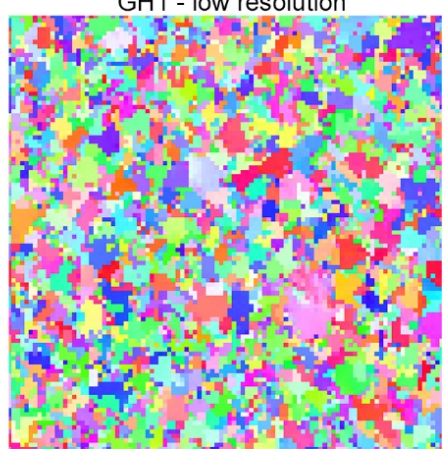

$\mathrm{BH}$ - very low resolution
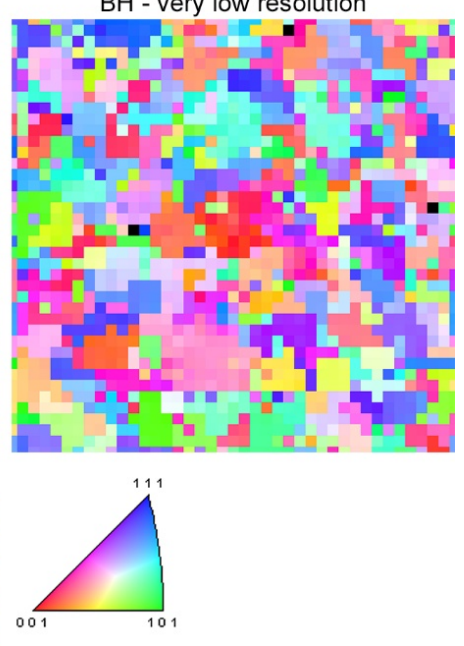

Figure 9 - Comparison of scans done at different resolutions for $\mathrm{BH}$ and GH1. "High resolution" corresponds to a step size of $3 \mu \mathrm{m}$, while "low resolution" has a step size of 10 $\mu \mathrm{m}$ and "very low resolution" is $25 \mu \mathrm{m}$. For the $\mathrm{BH}$ steel, the low- and very low-resolution scans were taken over an identical area. 
Based on the results obtained in this investigation, we propose to measure grain size on about $5 \%$, randomly selected, of the raw 4340 bars for newly purchased steel batches in the future. For each selected bar, small $\sim 10 \mathrm{~mm}$ long pieces can be cut off from the ends and microstructurally examined, with the expectation of measuring a grain size in the range 30 $\mu \mathrm{m}$ to $40 \mu \mathrm{m}$. These observations can be supported by HRC and HV measurements, which are also relatively fast and inexpensive. Instrumented Charpy testing is more expensive and time consuming, and is not recommended, unless previous investigations have provided conflicting results and some kind of "tie-breaker" is required.

Finally, we are also planning to measure grain size and hardness on 4340 batches that are currently in use and have proven to be of good quality in terms of acceptable Charpy lots produced by several Contractors. This will allow us to confirm and consolidate the expected properties of a "good" heat, in terms of grain size $(30 \mu \mathrm{m}$ to $40 \mu \mathrm{m})$ and Vickers hardness and (HV 205).

\section{References}

[1] ASTM E23-18, Standard Test Methods for Notched Bar Impact Testing of Metallic Materials, ASTM International, West Conshohocken, PA.

[2] D. Driscoll, Reproducibility of Charpy Impact Test, in ASTM STP 176, "Symposium on Impact Testing," F. Tatnall, ed., ASTM International, West Conshohocken, PA, 1956, pp 70-74. https://doi.org/978-0-8031-6912-8

[3] C. N. McCowan, T. A. Siewert, and D. P. Vigliotti, Charpy Verification Program: Reports Covering 1989-2002, NIST Technical Note 1500-9, National Institute of Standards and Technology, Boulder, Colorado, September 2003.

[4] ISO 148-2:2016, Metallic materials - Charpy pendulum impact test - Part 2: Verification of testing machines, International Standards Organization, Geneva, Switzerland.

[5] All Metals \& Forge Group, AISI / SAE 4340 Alloy Steel, https://steelforge.com/alloysteel-4340/, retrieved 7/26/2021.

[6] F. Grubbs, Procedures for Detecting Outlying Observations in Samples, Technometrics, 11(1), 1969, pp. 1-21. http://dx.doi.org/10.1080/00401706.1969.10490657

[7] W. Stefansky, Rejecting Outliers in Factorial Designs, Technometrics, 14, 1972, pp. 469479. http://dx.doi.org/10.1080/00401706.1972.10488930

[8] S. S. Shapiro and M. B. Wilk, An Analysis of Variance Test for Normality (Complete Samples), Biometrika, 52(3-4), 1965, pp. 591-611 https://doi.org/10.1093/biomet/52.3$\underline{4.591}$

[9] G. W. Snedecor and W. G. Cochran, Statistical Methods, Eighth Edition, Iowa State University Press, 1989. 


\section{Appendix A: Compositional and Melting Requirements (Specifications) for 4340 Steel}

1. The Contractor shall provide AISI 4340 steel bars, from a single heat to minimize compositional and microstructural variation. Because steel plants produce steel in different heat sizes (inherent to their facilities), $\mathrm{ACMD}^{7}$ will allow some flexibility in our contract by bracketing the quantity of the steel to be purchased and setting a maximum of $\$ 100,000$ for the purchase. We prefer to purchase the maximum quantity of steel possible.

2. The steel shall be produced using either a double-vacuum-melting procedure (vacuuminduction-melt vacuum-arc-remelt, VIM-VAR), or arc furnace melting followed by argonoxygen-decarburization (AOD) refining to produce electrodes which are vacuum arc remelted (ARC-AOD-VAR).

3. The steel shall meet the compositional requirements of AISI-SAE alloy 4340. Refer to http://www.steelforge.com/alloy-steel-4340/ for compositional information.

4. The steel must also meet the stricter requirements of AMS6414 (see http://standards.sae.org/ams6414/), which describes steel production by a vacuum-melting procedure.

5. ACMD also requires that the phosphorus, sulfur, vanadium, niobium, titanium, and copper contents of the steel to be low. The maximum concentrations (in mass \%) allowed for these elements shall be: (1) $\mathrm{P}=0.010$, (2) $\mathrm{S}=0.010$, (3) $\mathrm{V}=0.030$, (4) $\mathrm{Nb}=0.005$, (5) $\mathrm{Ti}=0.003$, and (6) $\mathrm{Cu}=0.35$.

6. The composition shall be certified using standard analytical procedures (such as optical emission spectroscopy or x-ray fluorescence), and the equipment shall be calibrated by standards traceable to NIST. The composition shall be measured at the top and bottom of the re-melted ingot. These two measurements shall be included in the documentation with the order, meet our compositional requirements, and meet the limits on residuals given in 5 . above. Deviations between the two measurements (in mass percent between the top and bottom of VAR ingot) cannot exceed 0.030 for $\mathrm{C}, \mathrm{Si}$, and $\mathrm{Mo} ; 0.10$ for $\mathrm{Mn}$; 0.030 for $\mathrm{Cr}$; 0.050 for $\mathrm{Ni}$; 0.003 for $\mathrm{P}$; and 0.001 for $\mathrm{S}$.

7. The ingots shall be forged, rolled to billet, conditioned, then hot rolled to bar (if an alternate process has not been mutually agreed upon). The goal of the processing is to have bar from one procurement to have inclusion distributions and sizes that are similar to batches produced from other procurements. With this objective in mind, it is required that the steel be processed in a manner agreed upon prior to the processing of the steel, such as:

a. VAR ingots at $1093{ }^{\circ} \mathrm{C}\left(2000^{\circ} \mathrm{F}\right)$ are forged to 12 by 11 inch billets that are rolled to $2 \frac{1 / 4}{4}$ inch diameter billets.

b. These billets are then solution annealed $\left(1100^{\circ} \mathrm{C} / 2012^{\circ} \mathrm{F}\right.$ for 1 hour, minimum) prior to rolling to $1 / 2$ inch square bar $\left(1093{ }^{\circ} \mathrm{C} / 2000^{\circ} \mathrm{F}\right)$.

c. If the solution treatment is performed as a separate process, controlled cooling (fans, quenching, etc.) is required down to a temperature of $500^{\circ} \mathrm{C}\left(930^{\circ} \mathrm{F}\right)$.

${ }^{7} \mathrm{ACMD}=$ Applied Chemicals and Materials Division of NIST (Boulder, Colorado). 
d. If the solution treatment is performed as part of the re-heating cycle prior to rolling, the process shall be described in adequate detail to indicate/estimate holding and cooling times.

8. The bar shall be finished to 0.50 -inch square bar ( +0.15 inch, -0.00 inch).

a. The corner radius of the finished bars cannot exceed 0.03 inches.

b. The microstructure shall be uniform through the thickness, with a maximum acceptable grain size of ASTM number 7.

c. In other attributes (decarburization, segregation, surface condition, etc.), the steel must be suitable for use as $10 \mathrm{~mm}$ square Charpy V-notch specimens.

9. The 0.50 -inch bar shall be fully annealed to a hardness of RB-95 max.

a. The bar shall be annealed at $850^{\circ} \mathrm{C}\left(1550^{\circ} \mathrm{F}\right)$ for 1 hour, furnace cooled at $10^{\circ} \mathrm{C} / \mathrm{hr}(50$ $\left.{ }^{\circ} \mathrm{F} / \mathrm{hr}\right)$ to $315^{\circ} \mathrm{C}\left(600^{\circ} \mathrm{F}\right)$, then air cooled to room temperature.

b. It is critical to produce a uniform hardness bar (no hard spots), because hard spots result in significant machining issues.

c. ACMD will accept alternate heat-treating schedules by mutual agreement.

The bars shall be machine straightened (for twist and bow), and shipped in lengths of no more than 6 feet. 


\section{Appendix B: Rockwell C Measurements on GH1 and BH Heats}

\begin{tabular}{|c|c|c|c|}
\hline \multicolumn{2}{|l|}{ GH1 } & \multicolumn{2}{|l|}{ BH } \\
\hline Specimen & HRC & Specimen & HRC \\
\hline 1 & 8.7 & 1 & 11.9 \\
\hline 2 & 10.6 & 2 & 13.8 \\
\hline 3 & 9.8 & 3 & 9.7 \\
\hline 4 & 13.9 & 4 & 12.6 \\
\hline 5 & 10.4 & 5 & 16 \\
\hline 6 & 10.8 & 6 & 13.3 \\
\hline 7 & 12.6 & 7 & 13.8 \\
\hline 8 & 10.2 & 8 & 12.3 \\
\hline 9 & 9.2 & 9 & 13.7 \\
\hline 10 & 8.6 & 10 & 17.1 \\
\hline 11 & 12.4 & 11 & 14.5 \\
\hline 12 & 14.6 & 12 & 14.6 \\
\hline 13 & 13 & 13 & 6.3 \\
\hline 14 & 8.5 & 14 & 12.4 \\
\hline 15 & 9.8 & 15 & 11.8 \\
\hline 16 & 10.7 & 16 & 13.6 \\
\hline 17 & 9.2 & 17 & 12.1 \\
\hline 18 & 14.0 & 18 & 10.8 \\
\hline 19 & 14.1 & 19 & 13.3 \\
\hline 20 & 9.7 & 20 & 13.0 \\
\hline 21 & 9.3 & 21 & 14.3 \\
\hline 22 & 12.8 & 22 & 12.9 \\
\hline 23 & 10.1 & 23 & 13.5 \\
\hline 24 & 9.6 & 24 & 11.5 \\
\hline 25 & 9.5 & 25 & 14 \\
\hline Average & 10.9 & Average & 12.9 \\
\hline Standard Deviation & 1.93 & Standard Deviation & 2.07 \\
\hline
\end{tabular}




\section{Appendix C: Absorbed Energy Results from GH1, GH2, and BH Heats}

\begin{tabular}{|c|c|c|c|c|c|}
\hline \multicolumn{2}{|l|}{ GH1 } & \multicolumn{2}{|l|}{ GH2 } & \multicolumn{2}{|l|}{ BH } \\
\hline Specimen & KV (J) & Specimen & KV (J) & Specimen & KV (J) \\
\hline 1 & 25.57 & 1 & 37.00 & 1 & 19.95 \\
\hline 2 & 29.69 & 2 & 30.32 & 2 & 18.67 \\
\hline 3 & 26.22 & 3 & 32.45 & 3 & 8.73 \\
\hline 4 & 26.04 & 4 & 22.76 & 4 & 17.74 \\
\hline 5 & 26.08 & 5 & 39.51 & 5 & 21.47 \\
\hline 6 & 27.17 & 6 & 26.44 & 6 & 18.80 \\
\hline 7 & 24.78 & 7 & 25.30 & 7 & 20.76 \\
\hline 8 & 29.55 & 8 & 37.63 & 8 & 20.17 \\
\hline 9 & 25.26 & 9 & 44.74 & 9 & 20.57 \\
\hline 10 & $17.25^{*}$ & 10 & 36.28 & 10 & 16.29 \\
\hline 11 & 30.10 & 11 & 26.44 & 11 & 16.13 \\
\hline 12 & 28.31 & 12 & 25.39 & 12 & 20.10 \\
\hline 13 & 26.66 & 13 & 24.34 & 13 & 19.57 \\
\hline 14 & 26.01 & 14 & 38.97 & 14 & 17.05 \\
\hline 15 & 25.29 & 15 & 33.07 & 15 & 18.64 \\
\hline 16 & 24.04 & 16 & 29.35 & 16 & 19.10 \\
\hline 17 & 26.04 & 17 & 38.07 & 17 & 22.28 \\
\hline 18 & 24.58 & 18 & 24.60 & 18 & 20.50 \\
\hline 19 & 29.48 & 19 & 25.91 & 19 & 9.53 \\
\hline 20 & 21.81 & 20 & 38.70 & 20 & 17.91 \\
\hline 21 & 28.34 & 21 & 41.31 & 21 & 15.02 \\
\hline 22 & 25.91 & 22 & 29.88 & 22 & 9.62 \\
\hline 23 & 26.28 & 23 & 40.50 & 23 & 17.28 \\
\hline 24 & 20.94 & 24 & 40.05 & 24 & 11.35 \\
\hline 25 & 24.58 & 25 & 33.43 & 25 & 15.83 \\
\hline Average & 25.84 & Average & 32.90 & Average & 17.32 \\
\hline Standard Deviation & 2.869 & Standard Deviation & 6.556 & Standard Deviation & 3.825 \\
\hline
\end{tabular}

"Statistical outlier (Grubbs' test). 


\section{Appendix D: Instrumented Impact Results from GH1 and BH Heats}

\begin{tabular}{|c|c|c|c|c|c|c|c|}
\hline \multicolumn{7}{|c|}{ GH1 Heat } \\
\hline $\begin{array}{c}\text { Specimen } \\
\text { ID }\end{array}$ & $\begin{array}{c}\boldsymbol{F}_{\boldsymbol{g} \boldsymbol{y}} \\
\mathbf{k N})\end{array}$ & $\begin{array}{c}\boldsymbol{F}_{\boldsymbol{m}} \\
\mathbf{( k N )}\end{array}$ & $\begin{array}{c}\boldsymbol{s}_{\boldsymbol{g} \boldsymbol{y}} \\
(\mathbf{m m})\end{array}$ & $\begin{array}{c}\boldsymbol{s}_{\boldsymbol{m}} \\
(\mathbf{m m})\end{array}$ & $\begin{array}{c}\boldsymbol{W}_{\boldsymbol{m}} \\
\mathbf{( J )}\end{array}$ & $\begin{array}{c}\boldsymbol{W}_{\boldsymbol{t}} \\
(\mathbf{J})\end{array}$ & $\begin{array}{c}\boldsymbol{C}_{\boldsymbol{e l}} \\
(\mathbf{m m} / \mathbf{k N})\end{array}$ \\
\hline GH1-1 & 14.44 & 19.55 & 0.27 & 1.53 & 22.33 & 24.07 & 0.00714 \\
\hline GH1-2 & 14.11 & 19.02 & 0.29 & 1.68 & 25.24 & 27.09 & 0.00737 \\
\hline GH1-3 & 13.02 & 19.44 & 0.27 & 1.65 & 24.49 & 26.12 & 0.00758 \\
\hline GH1-4 & 13.56 & 18.06 & 0.28 & 1.62 & 23.72 & 25.23 & 0.00897 \\
\hline GH1-5 & 13.92 & 18.27 & 0.28 & 1.57 & 22.86 & 24.63 & 0.00892 \\
\hline GH1-6 & 14.02 & 20.12 & 0.25 & 1.54 & 24.08 & 26.09 & 0.00723 \\
\hline GH1-7 & 12.51 & 17.89 & 0.26 & 1.63 & 23.36 & 24.75 & 0.00837 \\
\hline GH1-8 & 12.81 & 19.69 & 0.25 & 1.81 & 27.96 & 29.33 & 0.00823 \\
\hline GH1-9 & 13.22 & 18.87 & 0.25 & 1.59 & 23.79 & 25.22 & 0.00738 \\
\hline GH1-10 & 13.62 & 16.20 & 0.28 & 0.77 & 9.44 & 16.16 & 0.00918 \\
\hline GH1-11 & 12.53 & 20.13 & 0.29 & 1.83 & 27.55 & 29.14 & 0.00786 \\
\hline GH1-12 & 13.66 & 19.54 & 0.27 & 1.65 & 25.24 & 27.00 & 0.00772 \\
\hline GH1-13 & 12.94 & 19.32 & 0.25 & 1.62 & 24.47 & 26.22 & 0.00806 \\
\hline GH1-14 & 12.68 & 17.71 & 0.31 & 1.46 & 19.96 & 24.69 & 0.00874 \\
\hline GH1-15 & 13.41 & 17.74 & 0.27 & 1.58 & 22.79 & 24.27 & 0.00858 \\
\hline GH1-16 & 13.88 & 17.17 & 0.28 & 1.46 & 20.90 & 24.11 & 0.00847 \\
\hline GH1-17 & 12.86 & 18.18 & 0.26 & 1.62 & 23.75 & 25.28 & 0.00913 \\
\hline GH1-18 & 12.47 & 17.58 & 0.26 & 1.48 & 21.05 & 22.82 & 0.00828 \\
\hline GH1-19 & 13.94 & 19.19 & 0.27 & 1.76 & 27.18 & 28.80 & 0.00842 \\
\hline GH1-20 & 13.89 & 16.19 & 0.31 & 1.06 & 13.45 & 20.48 & 0.00830 \\
\hline GH1-21 & 12.88 & 19.38 & 0.26 & 1.73 & 26.02 & 27.60 & 0.00828 \\
\hline GH1-22 & 13.67 & 18.02 & 0.30 & 1.62 & 23.65 & 27.58 & 0.00857 \\
\hline GH1-23 & 13.45 & 18.17 & 0.27 & 1.55 & 22.78 & 26.67 & 0.00798 \\
\hline GH1-24 & 13.80 & 17.09 & 0.27 & 0.96 & 12.77 & 19.60 & 0.00788 \\
\hline GH1-25 & 13.70 & 18.03 & 0.30 & 1.58 & 22.92 & 24.31 & 0.00820 \\
\hline Mean & $\mathbf{1 3 . 4 0}$ & $\mathbf{1 8 . 4 2}$ & $\mathbf{0 . 2 7}$ & $\mathbf{1 . 5 3}$ & $\mathbf{2 2 . 4 7}$ & $\mathbf{2 5 . 0 9}$ & $\mathbf{0 . 0 0 8 1 9}$ \\
\hline Standard \\
Deviation & $\mathbf{0 . 5 7}$ & $\mathbf{1 . 1 1}$ & $\mathbf{0 . 0 2}$ & $\mathbf{0 . 2 5}$ & $\mathbf{4 . 4 7}$ & $\mathbf{2 . 9 9}$ & $\mathbf{0 . 0 0 0 5 8}$ \\
\hline CV & $\mathbf{4 . 2 \%}$ & $\mathbf{6 . 0 \%}$ & $\mathbf{6 . 6 \%}$ & $\mathbf{1 6 . 3 \%}$ & $\mathbf{1 9 . 9 \%}$ & $\mathbf{1 1 . 9 \%}$ & $\mathbf{7 . 1 \%}$ \\
\hline
\end{tabular}




\begin{tabular}{|c|c|c|c|c|c|c|c|}
\hline \multicolumn{7}{|c|}{ BH Heat } \\
\hline $\begin{array}{c}\text { Specimen } \\
\text { ID }\end{array}$ & $\begin{array}{c}\boldsymbol{F}_{\boldsymbol{g} \boldsymbol{y}} \\
\mathbf{( k N )}\end{array}$ & $\begin{array}{c}\boldsymbol{F}_{\boldsymbol{m}} \\
\mathbf{( k N )}\end{array}$ & $\begin{array}{c}\boldsymbol{s g}_{\boldsymbol{g} \boldsymbol{y}} \\
(\mathbf{m m})\end{array}$ & $\begin{array}{c}\boldsymbol{s}_{\boldsymbol{m}} \\
(\mathbf{m m})\end{array}$ & $\begin{array}{c}\boldsymbol{W}_{\boldsymbol{m}} \\
(\mathbf{J})\end{array}$ & $\begin{array}{c}\boldsymbol{W}_{\boldsymbol{t}} \\
(\mathbf{J})\end{array}$ & $\begin{array}{c}\boldsymbol{C}_{\boldsymbol{e l}} \\
(\mathbf{m m} / \mathbf{k N})\end{array}$ \\
\hline BH-1 & 13.51 & 16.82 & 0.27 & 0.91 & 11.94 & 19.40 & 0.00846 \\
\hline BH-2 & 12.11 & 17.21 & 0.29 & 1.12 & 14.40 & 18.86 & 0.00828 \\
\hline BH-3 & N/A & 16.01 & N/A & 0.31 & 2.20 & 8.41 & 0.01031 \\
\hline BH-4 & 12.68 & 16.53 & 0.25 & 1.24 & 16.79 & 21.72 & 0.00815 \\
\hline BH-5 & 13.95 & 16.13 & 0.28 & 0.86 & 10.66 & 17.25 & 0.01025 \\
\hline BH-6 & 14.61 & 16.58 & 0.27 & 0.98 & 13.07 & 19.32 & 0.00806 \\
\hline BH-7 & 14.73 & 17.27 & 0.26 & 1.19 & 17.22 & 20.23 & 0.00801 \\
\hline BH-8 & 14.37 & 16.18 & 0.27 & 1.12 & 15.00 & 20.19 & 0.00802 \\
\hline BH-9 & 14.92 & 17.16 & 0.26 & 1.34 & 19.42 & 20.72 & 0.00882 \\
\hline BH-10 & 12.33 & 16.37 & 0.27 & 0.80 & 9.76 & 16.21 & 0.00910 \\
\hline BH-11 & 13.72 & 16.38 & 0.27 & 0.77 & 9.69 & 16.36 & 0.00793 \\
\hline BH-12 & 12.97 & 16.35 & 0.26 & 1.16 & 15.44 & 20.84 & 0.01010 \\
\hline BH-13 & 14.10 & 16.02 & 0.27 & 1.07 & 14.12 & 19.12 & 0.00796 \\
\hline BH-14 & 14.15 & 16.57 & 0.29 & 0.84 & 10.66 & 17.69 & 0.00846 \\
\hline BH-15 & 14.97 & 16.56 & 0.27 & 0.82 & 10.84 & 18.60 & 0.00928 \\
\hline BH-16 & 14.15 & 16.65 & 0.29 & 1.09 & 14.09 & 19.38 & 0.00967 \\
\hline BH-17 & 15.26 & 17.94 & 0.28 & 1.45 & 21.51 & 22.97 & 0.00947 \\
\hline BH-18 & 13.82 & 16.97 & 0.27 & 1.42 & 20.30 & 21.72 & 0.00796 \\
\hline BH-19 & N/A & 16.10 & N/A & 0.45 & 4.52 & 6.80 & 0.02379 \\
\hline BH-20 & 14.29 & 16.79 & 0.30 & 0.86 & 10.90 & 18.23 & 0.00854 \\
\hline BH-21 & & & \multicolumn{2}{|l|}{ Instrumented data not acquired } & & \\
\hline BH-22 & N/A & 17.54 & N/A & 0.49 & 4.85 & 7.72 & 0.02163 \\
\hline BH-23 & 14.07 & 15.80 & 0.27 & 0.81 & 10.19 & 17.64 & 0.00940 \\
\hline BH-24 & 15.11 & 17.51 & 0.27 & 0.67 & 8.25 & 10.00 & 0.00993 \\
\hline BH-25 & 13.55 & 17.39 & 0.26 & 0.70 & 8.97 & 15.45 & 0.00850 \\
\hline Mean & $\mathbf{1 3 . 9 7}$ & $\mathbf{1 6 . 7 0}$ & $\mathbf{0 . 2 7}$ & $\mathbf{0 . 9 4}$ & $\mathbf{1 2 . 2 8}$ & $\mathbf{1 7 . 2 8}$ & $\mathbf{0 . 0 1 0 0 0}$ \\
\hline $\begin{array}{c}\text { Standard } \\
\text { Deviation }\end{array}$ & $\mathbf{0 . 8 8}$ & $\mathbf{0 . 5 7}$ & $\mathbf{0 . 0 1}$ & $\mathbf{0 . 3 0}$ & $\mathbf{4 . 8 7}$ & $\mathbf{4 . 5 4}$ & $\mathbf{0 . 0 0 4 0 0}$ \\
\hline CV & $\mathbf{6 . 3 \%}$ & $\mathbf{3 . 4 \%}$ & $\mathbf{4 . 5 \%}$ & $\mathbf{3 1 . 7 \%}$ & $\mathbf{3 9 . 6 \%}$ & $\mathbf{2 6 . 3 \%}$ & $\mathbf{4 0 . 0 \%}$ \\
\hline
\end{tabular}

N/A = not available (brittle behavior - general yield point not detected). 


\section{Appendix E: Optical Microscopy of GH1 and BH Heats}

Several immediate observations can be made from the optical images. First, the samples appear to be fairly homogenous along the different directions. There are no large gradients in grain size, secondary phases, or macrostructure across the observed planes. Second, there is evidence of a directional macrostructure in the Z-direction, which is more prominent in the good steel than in the bad, reminiscent of that derived from rolling-type processing. This macrostructure is unsurprising given the forming process for a square cross-section bar.

\section{GH1 - Z-plane}

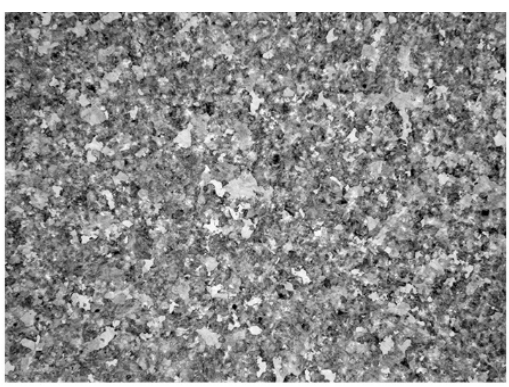

$+\mathrm{y}$
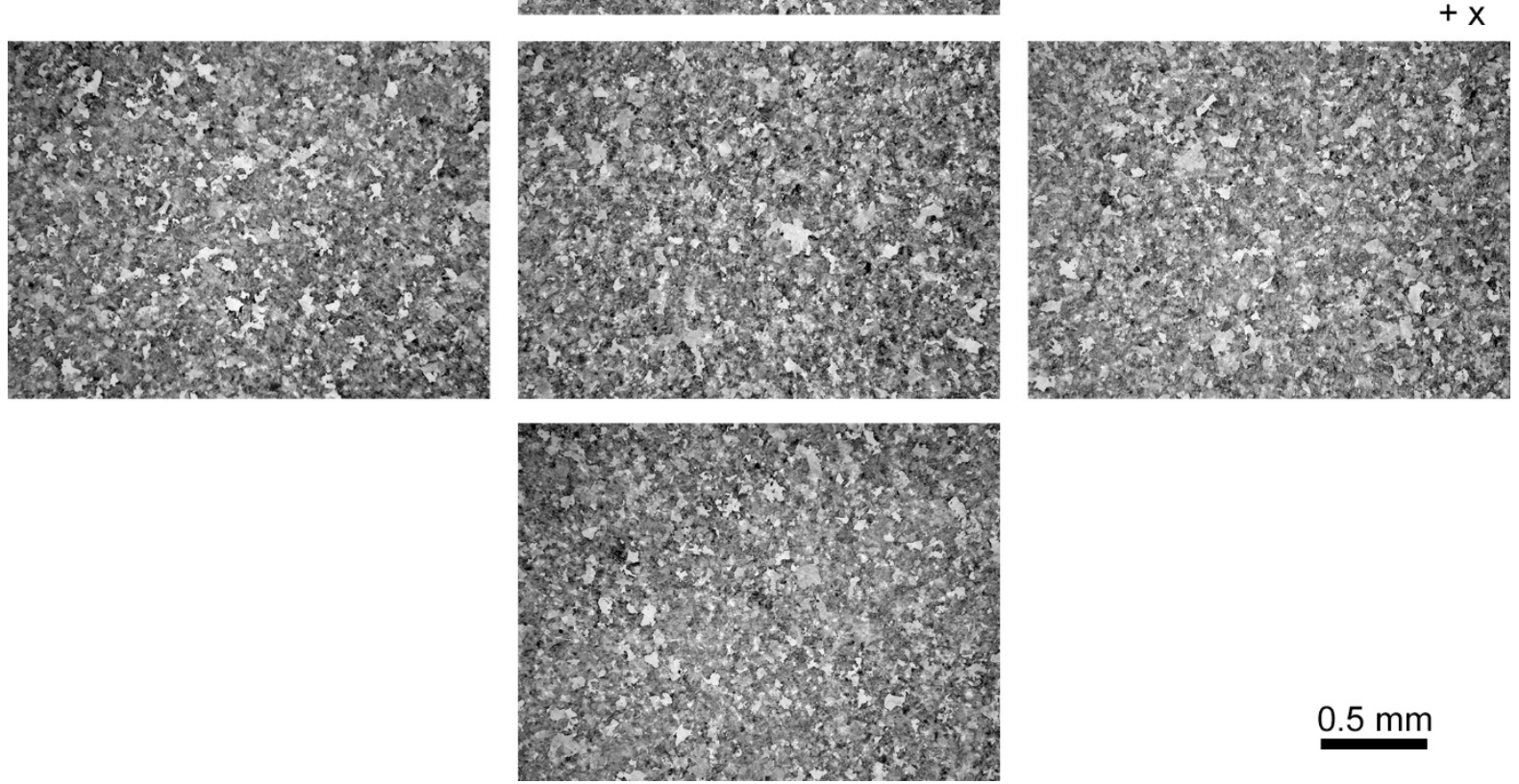

$0.5 \mathrm{~mm}$ 

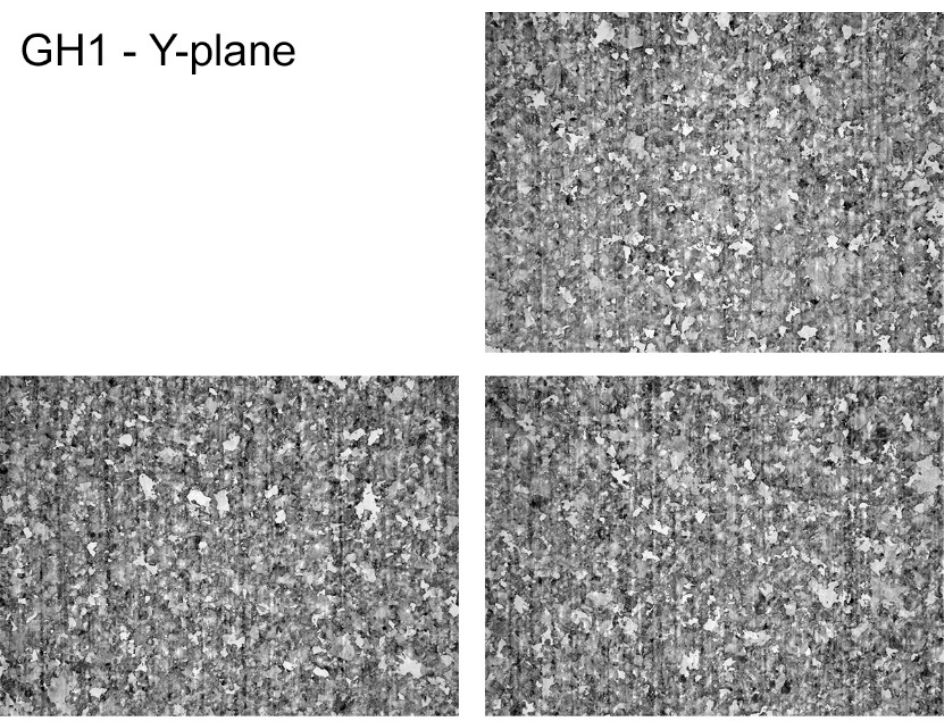

$+z$
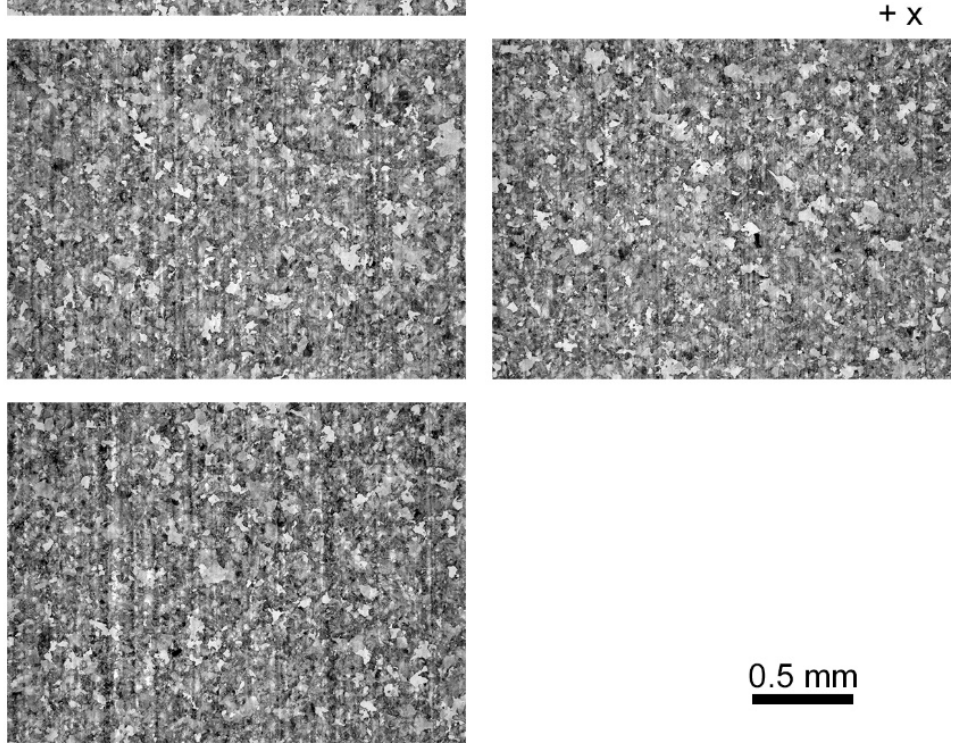

$0.5 \mathrm{~mm}$

\section{GH1 - X-plane}

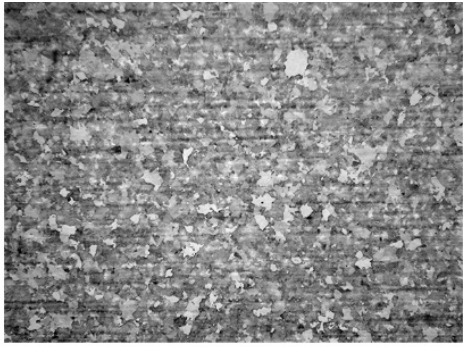

$+y$
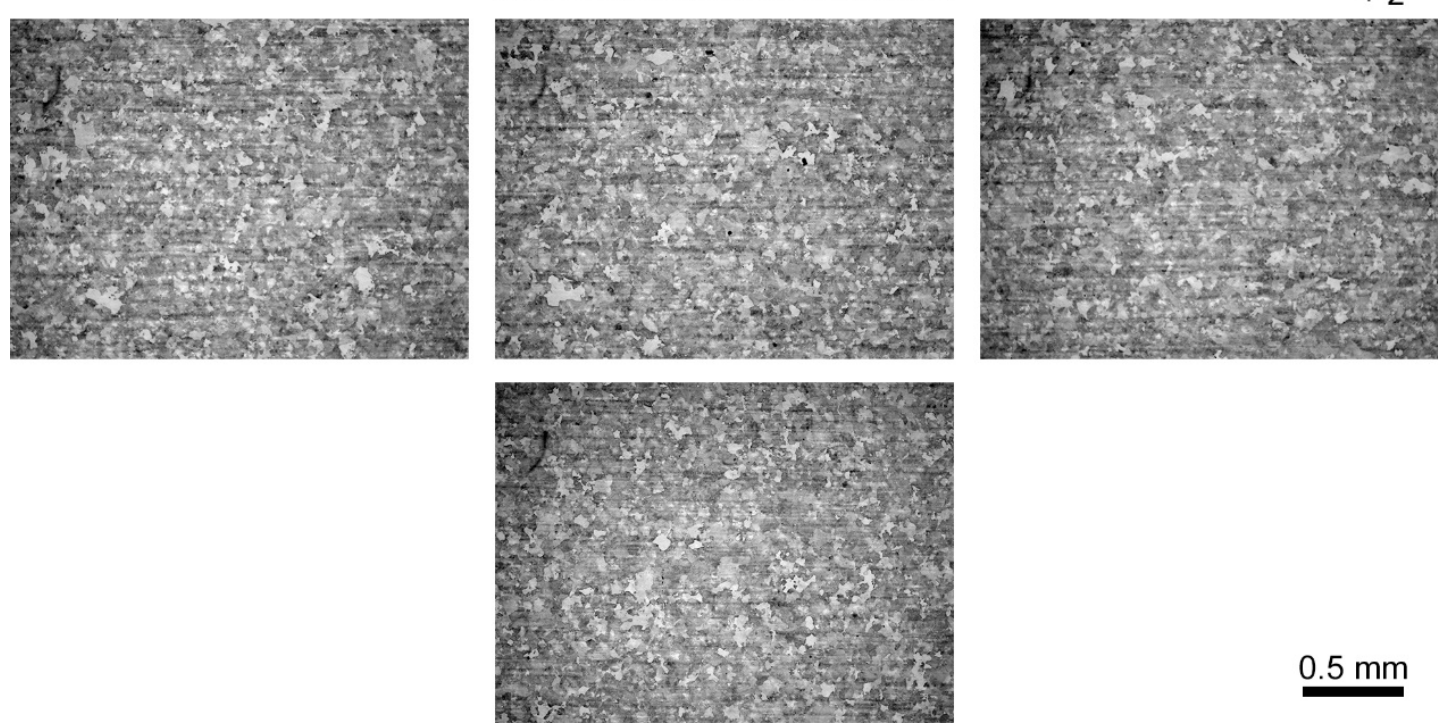


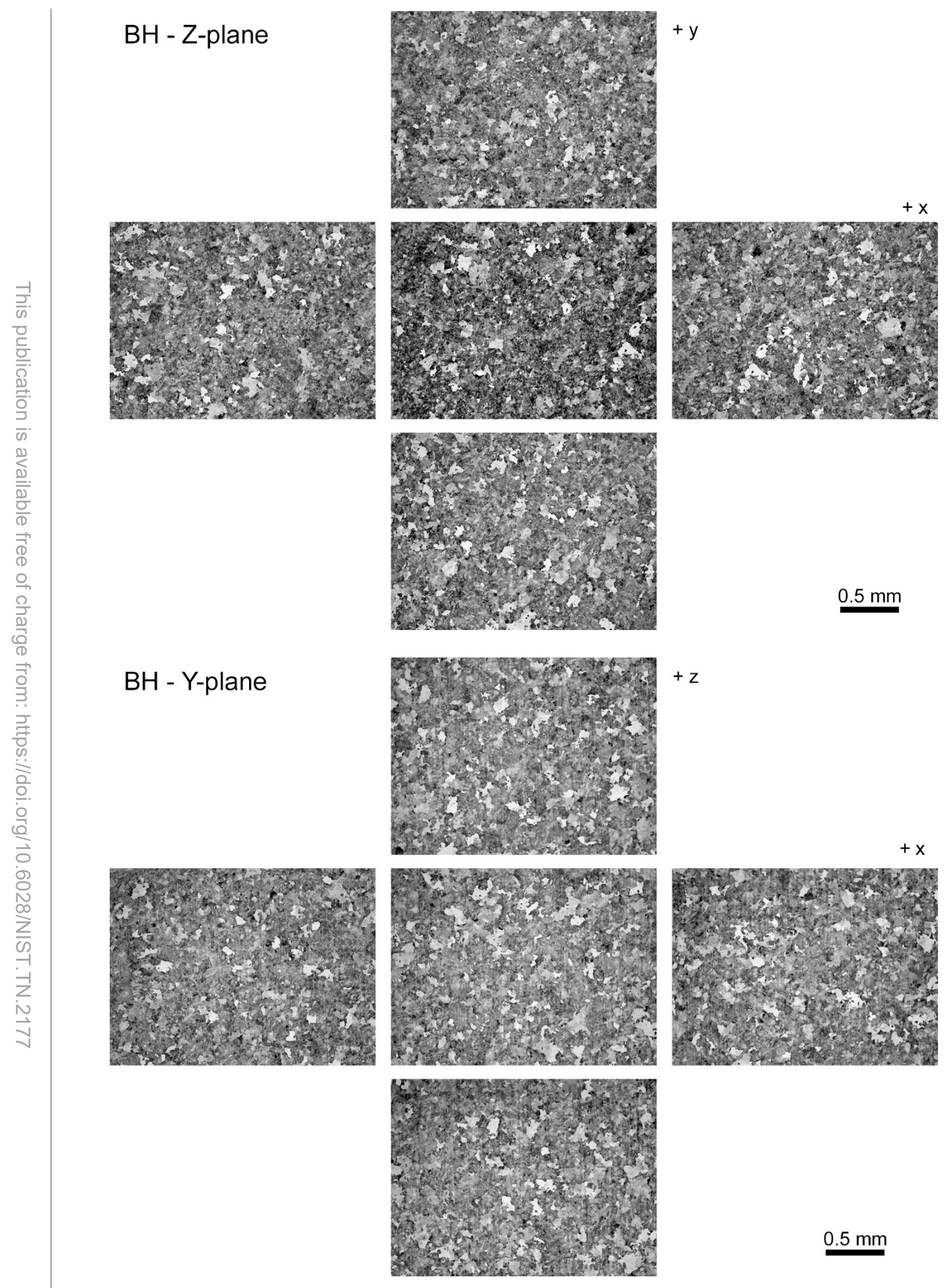


$\mathrm{BH}$ - X-plane
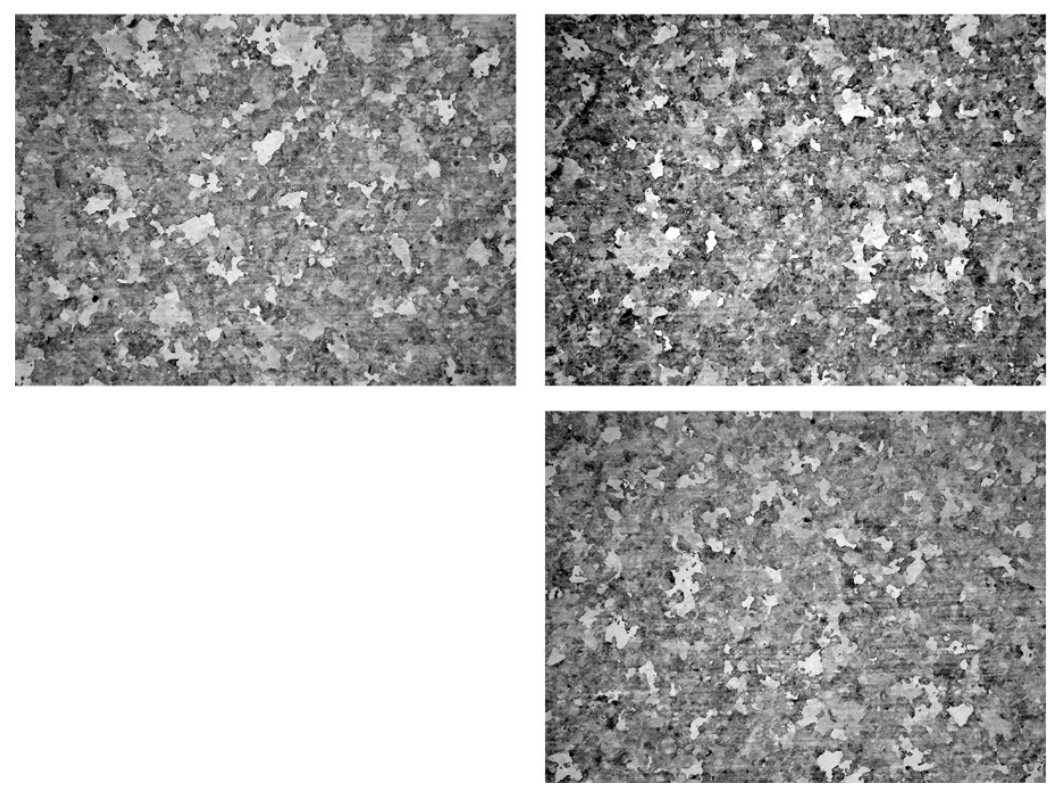

$+y$

$+z$

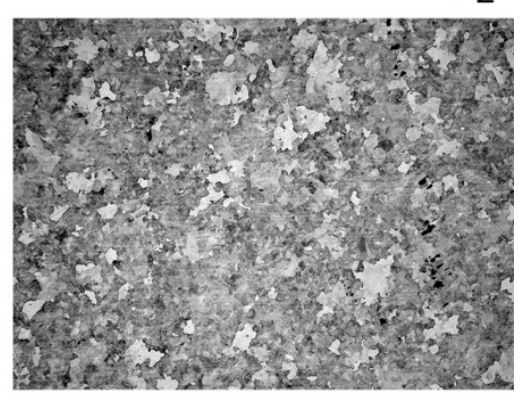

$0.5 \mathrm{~mm}$ 


\section{Appendix F: EBSD Data for GH1 and BH Heats}

EBSD analysis was performed on a SEM operated at $30 \mathrm{kV}$. Scan sizes were $1 \mathrm{~mm}$ x $1 \mathrm{~mm}$ with a step size between 1 and $4 \mu \mathrm{m}$ to best capture the range of grain sizes as well as sufficient data for texture analysis. These scans take between 6 and 12 hours, depending upon the step size and the EBSD camera settings (which are based upon the electron gun performance during the scan). Two of the scans, both of which were run overnight, failed to complete due to power fluctuations changing the performance of the gun sufficient to prevent data from being collected. However, as these two scans were between 60 and $80 \%$ completed, it was determined that sufficient data had been collected for the scans to be useful.

The EBSD data presented here is the orientation mapping showing coloring based on the crystallographic direction perpendicular to the scan plane normal. For presentation in this report, most of the maps underwent a standard "clean-up" procedure, whereby low quality data points surrounded by high quality points are reassigned a value based upon the high quality points, reducing noise in the image. This procedure is commonly used in EBSD data presentation, but its use is frequently unreported. It typically results in a change in less than $10 \%$ of the data points. Also, presented here are some texture data for the direction perpendicular to the scan plan normal. Texture analysis is an automated process where the orientation information of each pixel is binned and presented as heat map inverse pole figures. This indicates which orientations are the most common. These pole figures have been normalized to the same intensity scale. 


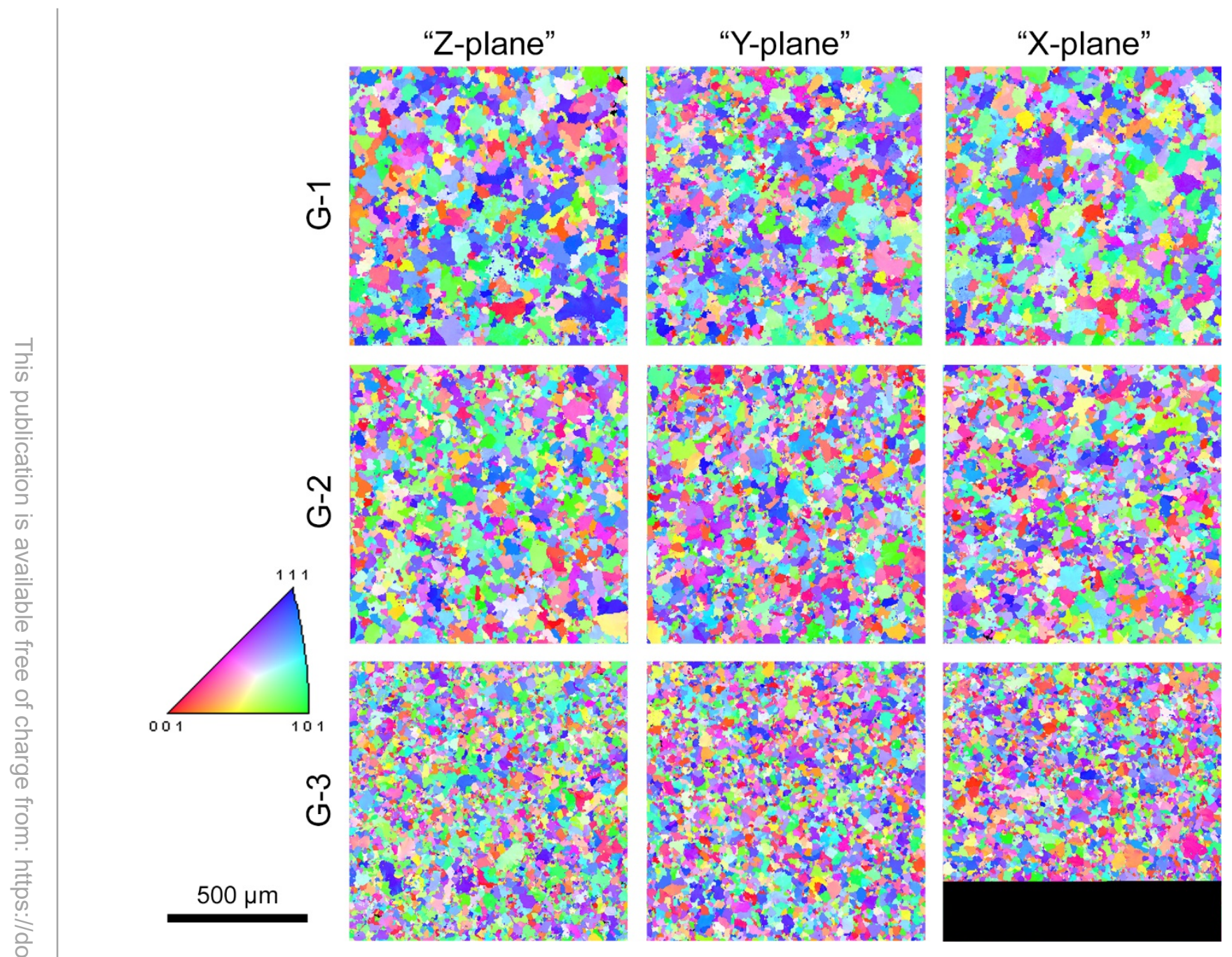



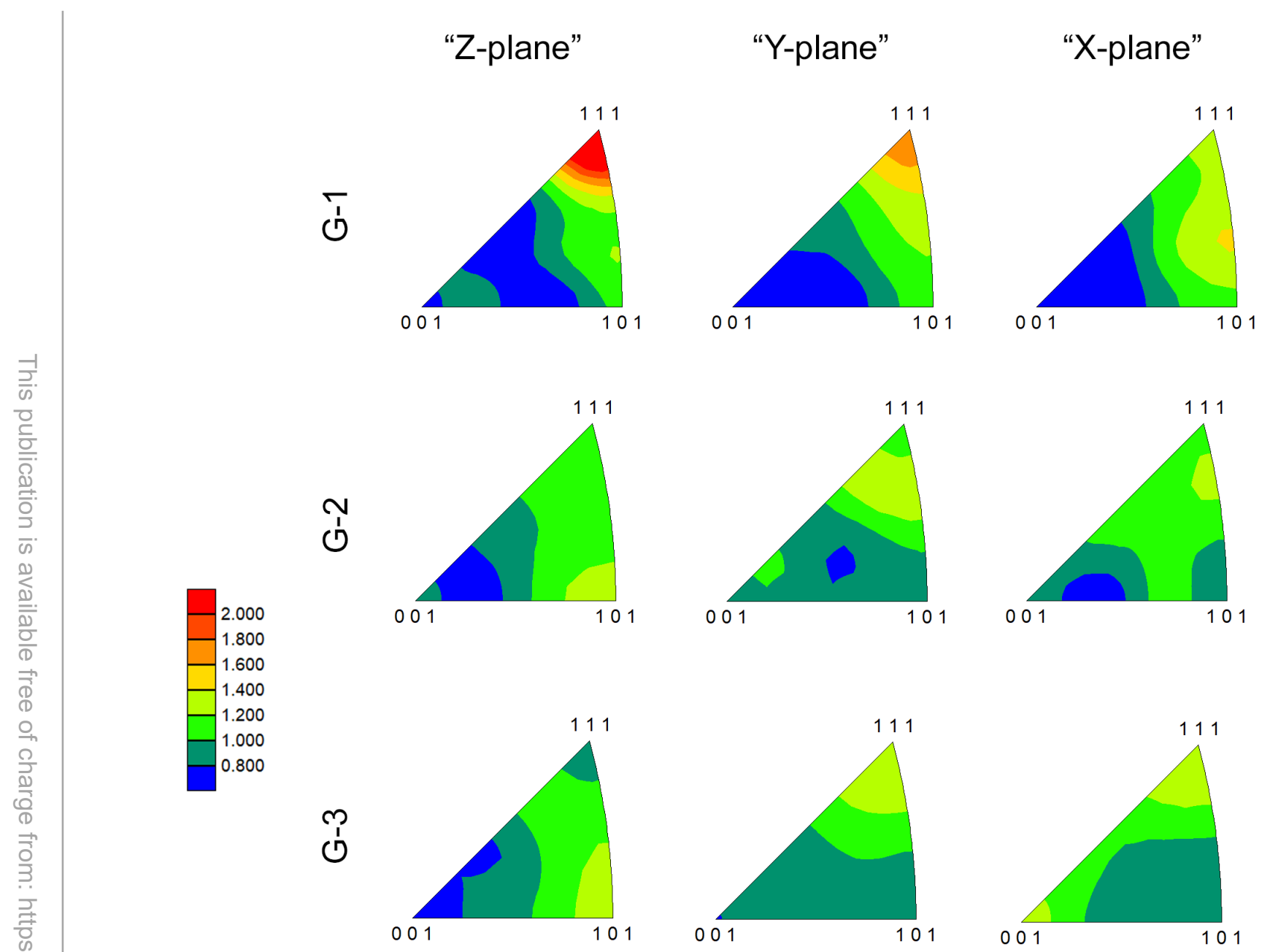


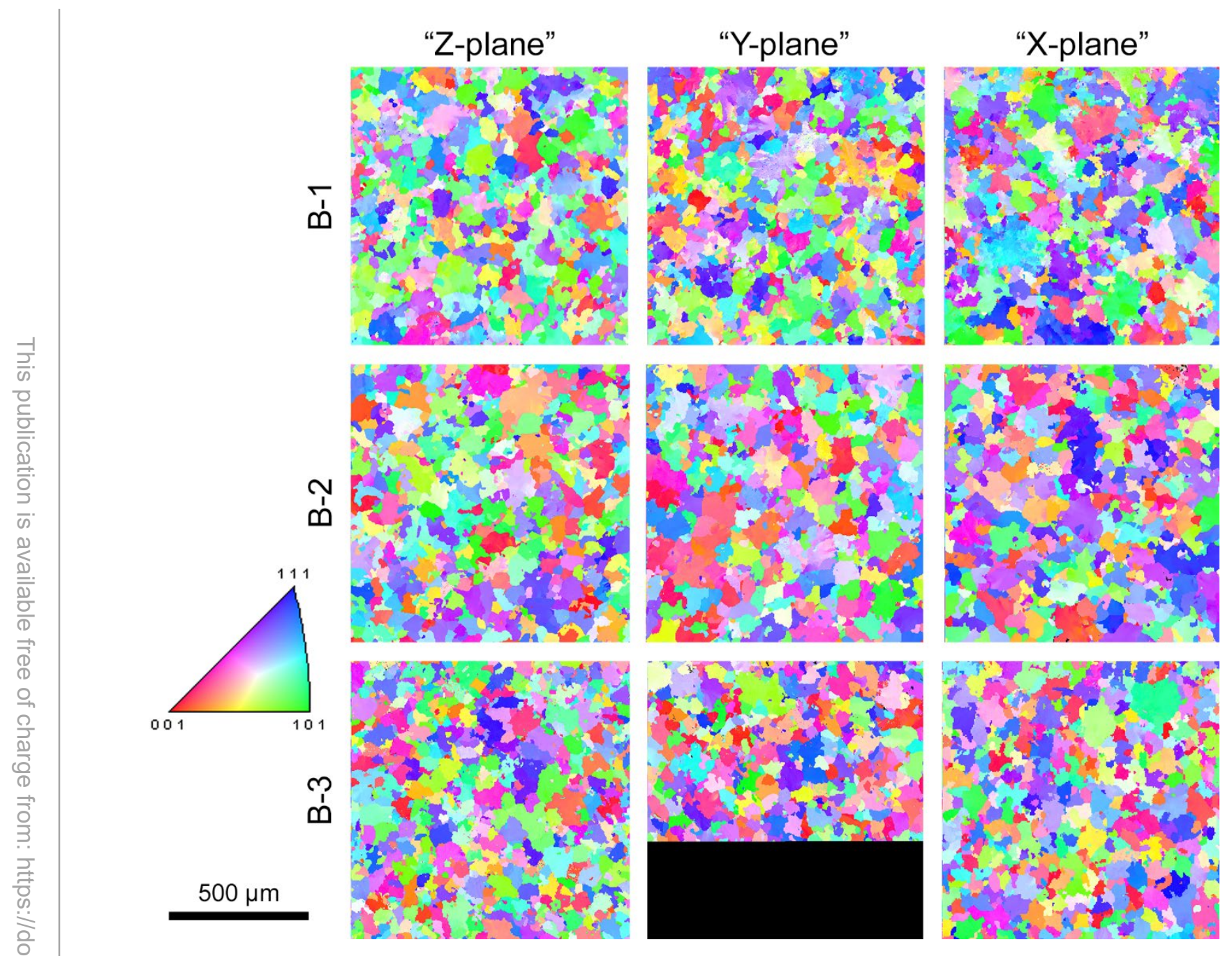



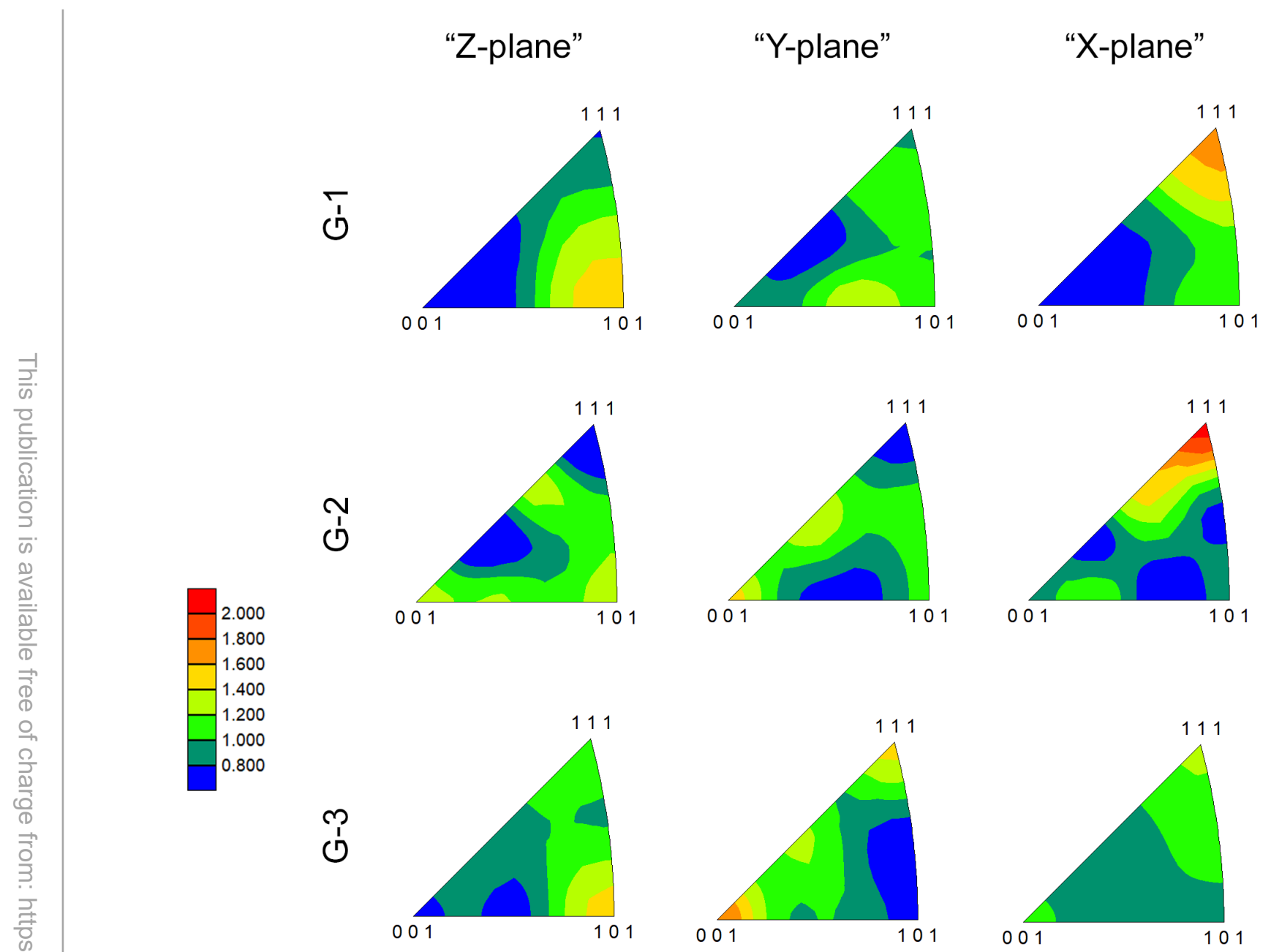


\section{Appendix G: Vickers Microhardness Measurements on GH1 and BH Heats}

\begin{tabular}{|c|c|c|c|c|c|c|}
\hline \multicolumn{7}{|c|}{ GH1 Heat } \\
\hline \multirow{2}{*}{$\begin{array}{c}\text { Position } \\
\text { (mm) }\end{array}$} & \multicolumn{2}{|c|}{$\mathrm{X}$-axis } & \multicolumn{2}{|c|}{$Y$-axis } & \multicolumn{2}{|c|}{ Z-axis } \\
\hline & 1 & 2 & 1 & 3 & 2 & 3 \\
\hline 0 & 212 & 206 & 203 & 214 & 201 & 206 \\
\hline 0.5 & 202 & 203 & 202 & 207 & 200 & 197 \\
\hline 1 & 200 & 203 & 196 & 210 & 217 & 205 \\
\hline 1.5 & 202 & 208 & 198 & 204 & 208 & 207 \\
\hline 2 & 199 & 205 & 212 & 193 & 205 & 215 \\
\hline 2.5 & 204 & 206 & 205 & 199 & 215 & 198 \\
\hline 3 & 214 & 210 & 198 & 203 & 204 & 212 \\
\hline 3.5 & 207 & 204 & 194 & 225 & 194 & 215 \\
\hline 4 & 204 & 210 & 214 & 204 & 200 & 214 \\
\hline 4.5 & 198 & 203 & 213 & 191 & 202 & 198 \\
\hline 5 & 203 & 211 & 205 & 207 & 204 & 198 \\
\hline 5.5 & 206 & 219 & 207 & 210 & 202 & 212 \\
\hline 6 & 195 & 209 & 209 & 206 & 202 & 209 \\
\hline 6.5 & 196 & 210 & 207 & 203 & 204 & 198 \\
\hline 7 & 210 & 198 & 196 & 206 & 207 & 200 \\
\hline 7.5 & 214 & 204 & 206 & 211 & 197 & 210 \\
\hline 8 & 210 & 212 & 204 & 203 & 209 & 203 \\
\hline 8.5 & 199 & 206 & 209 & 217 & 205 & 214 \\
\hline 9 & 194 & 205 & 201 & 211 & 208 & 208 \\
\hline 9.5 & 200 & 208 & 207 & 210 & & 206 \\
\hline Average & 203.5 & 207.0 & 204.3 & 206.7 & 204.4 & 206.3 \\
\hline $\begin{array}{l}\text { Standard } \\
\text { Deviation } \\
\end{array}$ & 6.1 & 4.4 & 5.8 & 7.7 & 5.6 & 6.4 \\
\hline CV & $3.0 \%$ & $2.1 \%$ & $2.8 \%$ & $3.7 \%$ & $2.7 \%$ & $3.1 \%$ \\
\hline
\end{tabular}




\begin{tabular}{|c|c|c|c|c|c|c|}
\hline \multirow{2}{*}{$\begin{array}{c}\text { Position } \\
(\mathbf{m m})\end{array}$} & \multicolumn{2}{|c}{ X-axis } & \multicolumn{2}{c|}{ Y-axis } & \multicolumn{2}{c|}{ Z-axis } \\
\cline { 2 - 7 } & $\mathbf{1}$ & $\mathbf{2}$ & $\mathbf{1}$ & $\mathbf{3}$ & $\mathbf{2}$ & $\mathbf{3}$ \\
\hline 0 & 217 & 226 & 232 & 230 & 226 & 224 \\
\hline 0.5 & 231 & 223 & 215 & 222 & 223 & 216 \\
\hline 1 & 224 & 214 & 211 & 224 & 214 & 217 \\
\hline 1.5 & 215 & 205 & 214 & 221 & 205 & 230 \\
\hline 2 & 216 & 218 & 214 & 223 & 218 & 222 \\
\hline 2.5 & 216 & 214 & 216 & 209 & 214 & 227 \\
\hline 3 & 216 & 205 & 207 & 213 & 205 & 216 \\
\hline 3.5 & 216 & 229 & 203 & 212 & 229 & 216 \\
\hline 4 & 204 & 216 & 227 & 221 & 216 & 234 \\
\hline 4.5 & 209 & 214 & 218 & 217 & 214 & 238 \\
\hline 5 & 217 & 216 & 213 & 221 & 216 & 226 \\
\hline 5.5 & 211 & 206 & 213 & 221 & 206 & 216 \\
\hline 6 & 213 & 214 & 203 & 217 & 214 & 220 \\
\hline 6.5 & 219 & 209 & 218 & 212 & 209 & 220 \\
\hline 7 & 211 & 210 & 202 & 212 & 210 & 216 \\
\hline 7.5 & 218 & 209 & 213 & 211 & 209 & 227 \\
\hline 8 & 229 & 221 & 215 & 221 & 221 & 217 \\
\hline 8.5 & 216 & 219 & 220 & 231 & 219 & 219 \\
\hline 9 & 216 & 209 & 213 & 220 & 209 & 226 \\
\hline 9.5 & 216 & 218 & 221 & 210 & 218 & 216 \\
\hline $\begin{array}{c}\text { Average } \\
\text { Dtandard }\end{array}$ & $\mathbf{2 1 6 . 5}$ & $\mathbf{2 1 4 . 8}$ & $\mathbf{2 1 4 . 4}$ & $\mathbf{2 1 8 . 4}$ & $\mathbf{2 1 4 . 8}$ & $\mathbf{2 2 2 . 2}$ \\
\hline Ceviation & $\mathbf{6 . 2}$ & $\mathbf{6 . 8}$ & $\mathbf{7 . 5}$ & $\mathbf{6 . 3}$ & $\mathbf{6 . 8}$ & $\mathbf{6 . 6}$ \\
\hline & $\mathbf{2 . 8 \%}$ & $\mathbf{3 . 2 \%}$ & $\mathbf{3 . 5 \%}$ & $\mathbf{2 . 9 \%}$ & $\mathbf{3 . 2 \%}$ & $\mathbf{3 . 0 \%}$ \\
\hline
\end{tabular}




\section{Appendix H: Vickers Microhardness Measurements on BL-1 and BL-2 Blanks}

\begin{tabular}{|c|c|c|c|c|}
\hline \multirow{2}{*}{$\begin{array}{c}\text { Position } \\
(\mathbf{m m})\end{array}$} & \multicolumn{2}{|c|}{ BL-1 blank } & \multicolumn{2}{|c|}{ BL-2 blank } \\
\hline & $\mathrm{X}$-axis & Y-axis & $\mathrm{X}$-axis & Y-axis \\
\hline 0 & 228 & 208 & 221 & 216 \\
\hline 0.5 & 221 & 219 & 220 & 222 \\
\hline 1 & 206 & 213 & 222 & 212 \\
\hline 1.5 & 229 & 220 & 206 & 202 \\
\hline 2 & 218 & 240 & 211 & 212 \\
\hline 2.5 & 205 & 206 & 208 & 207 \\
\hline 3 & 210 & 216 & 212 & 216 \\
\hline 3.5 & 208 & 205 & 206 & 205 \\
\hline 4 & 215 & 215 & 202 & 196 \\
\hline 4.5 & 204 & 197 & 205 & 206 \\
\hline 5 & 230 & 243 & 210 & 226 \\
\hline 5.5 & 215 & 203 & 218 & 221 \\
\hline 6 & 213 & 208 & 208 & 206 \\
\hline 6.5 & 219 & 232 & 207 & 218 \\
\hline 7 & 223 & 216 & 203 & 211 \\
\hline 7.5 & 208 & 200 & 216 & 212 \\
\hline 8 & 192 & 209 & 205 & 218 \\
\hline 8.5 & 212 & 220 & 220 & 220 \\
\hline 9 & 218 & 216 & 204 & 225 \\
\hline 9.5 & 210 & 234 & 214 & 204 \\
\hline Average & 214.2 & 216.0 & 210.9 & 212.8 \\
\hline $\begin{array}{l}\text { Standard } \\
\text { Deviation }\end{array}$ & 9.5 & 12.8 & 6.6 & 8.2 \\
\hline CV & $4.4 \%$ & $5.9 \%$ & $3.1 \%$ & $3.8 \%$ \\
\hline
\end{tabular}

